\title{
DISENTANGLING GEOMAGNETIC AND PRECIPITATION SIGNALS IN AN 80-KYR CHINESE LOESS RECORD OF ${ }^{10} \mathrm{Be}$
}

\author{
Weijian Zhou ${ }^{1,2} \bullet$ Alfred Priller $^{3} \bullet \mathrm{J}$ Warren Beck ${ }^{4} \bullet$ Wu Zhengkun $^{1} \bullet$ Chen Maobai ${ }^{1,5} \bullet$ \\ An Zhisheng ${ }^{1} \bullet$ Walter Kutschera ${ }^{3} \cdot$ Xian Feng $^{1} \bullet$ Yu Huagui $^{1} \bullet$ Liu Lin $^{1}$
}

\begin{abstract}
The cosmogenic radionuclide ${ }^{10} \mathrm{Be}$ is produced by cosmic-ray spallation in Earth's atmosphere. Its production rate is regulated by the geomagnetic field intensity, so that its accumulation rate in aeolian sediments can, in principle, be used to derive high-resolution records of geomagnetic field changes. However, ${ }^{10} \mathrm{Be}$ atmospheric fallout rate also varies locally depending on rainfall rate. The accumulation rate of ${ }^{10} \mathrm{Be}$ in sediments is further complicated by overprinting of the geomagnetic and precipitation signals by ${ }^{10} \mathrm{Be}$ attached to remobilized dust, which fell from the atmosphere at some time in the past. Here, we demonstrate that these signals can be deconvoluted to derive both geomagnetic field intensity and paleoprecipitation records of Asian Monsoon intensity in an 80,000-yr-long ${ }^{10} \mathrm{Be}$ record from Chinese loess. The strong similarity between our derived paleomagnetic intensity record and the SINT 200 (Guyodo and Valet 1996) and NAPIS 75 (Laj et al. 2002) stackedmarine records suggests that this method might be used to produce multimillion-yr-long records of paleomagnetic intensity from loess. This technique also reveals a new method for extracting quantitative paleoprecipitation records from continental interior regions. Our derived precipitation record is broadly similar to the speleothem $\delta^{18} \mathrm{O}$-based records of paleo-Asian Monsoon intensity from Dongge (Yuan et al. 2004) and Hulu (Wang et al. 2001) caves, and suggests that the paleo-Asian Monsoon intensity may be responding to a combination of both Northern and Southern Hemisphere insolation forcing.
\end{abstract}

\section{INTRODUCTION}

Wind-blown loess sediments have been accumulating in central China nearly continuously for the last 2.6 million yr (Liu and Ding 1998). These sediments are a storehouse of very long and potentially high-resolution records of both variations in the geomagnetic field, and of variability in the East Asian Monsoon. While there have been numerous previous efforts to extract climate or magnetic intensity records from Chinese loess (An et al. 2000; Beer et al. 1993, 2002; Evans and Heller 2001; Gu et al. 1996; Kukla et al. 1990; Maher and Thompson 1995; Pan et al. 2001; Porter et al. 2001; Shen et al. 1992; Zheng et al. 1995), the exercise has proved challenging because the climate and geomagnetic signals contained in these sediments are tightly intertwined. This is true for both magnetic susceptibility as well as for records of cosmogenic isotopes found in loess, such as ${ }^{10} \mathrm{Be}$, both of which have been used in attempts to reconstruct climate and geomagnetic field variations. For paleomagnetic reconstructions based on ${ }^{10} \mathrm{Be}$, some ${ }^{10} \mathrm{Be}$ comes from remobilized dust that fell to Earth at some time in the past, whereas a second component derives from atmospheric fallout of new ${ }^{10} \mathrm{Be}$ recently generated by cosmic-ray interactions in the atmosphere. It is the flux of this fallout component that is regulated by the geomagnetic field intensity. Unfortunately, interpretation of fallout ${ }^{10} \mathrm{Be}$ is further complicated by the fact that some of it makes its way to the ground via adsorption onto dry particulates, but the rest arrives by wet precipitation (Wallbrink and Murray 1994). While the dry fallout fraction is usually less than $10 \%$ (Wallbrink and Murray 1994), the local ${ }^{10} \mathrm{Be}$ fallout flux to the ground depends strongly on the wet precipitation amount. To further complicate matters, solar magnetic field variations can also influence atmospheric ${ }^{10} \mathrm{Be}$ production via fluctuations in solar wind rigidity (Masarik and Beer 1999), though solar forcing mainly acts on shorter periods than are being considered here.

\footnotetext{
${ }^{1}$ State Key Laboratory of Loess and Quaternary Geology, Institute of Earth Environment, Chinese Academy of Sciences, No. 10 Fenghui South Road, Hi-tech Zone, Xi'an 710075, China.

${ }^{2} \mathrm{Xi}$ 'an AMS Center, Xi' an 710075 China. Corresponding author. Email: weijian@loess.llqg.ac.cn.

${ }^{3}$ VERA (Vienna Environmental Research Accelerator), University of Vienna, Währinger, Str. 17, 1090 Vienna, Austria.

${ }^{4}$ NSF-Arizona AMS Facility, Physics Department, Building \#81, University of Arizona, Tucson, Arizona 85721, USA.

${ }^{5}$ Shanghai Institute of Applied Physics, Chinese Academy of Sciences, Shanghai 201800, China.
} 
In this paper, we argue that the amount of magnetic susceptibility and ${ }^{10} \mathrm{Be}$ associated with recycled dust can be calculated and eliminated by using magnetic coercivity and magnetic susceptibility measurements together. Once the recycled dust effects are removed, we will show that the residual susceptibility and ${ }^{10} \mathrm{Be}$ signals are controlled by a combination of both climate and geomagnetic field intensity. Because both signals are overprinted by climate in a similar manner, their cross-correlation offers a simple way to remove the climate contamination from the ${ }^{10} \mathrm{Be}$ record, yielding a signal dependent only on geomagnetic field intensity. Once the geomagnetic field signal is extracted, we are then able to recover a record of paleorainfall intensity by the separation of variables.

Other authors have previously noted that magnetic susceptibility (intensity of magnetization/unit mass in response to a defined applied field) and ${ }^{10} \mathrm{Be}$ concentration in Chinese loess are correlated with rainfall (Beer et al. 1993, 2002; Heller et al. 1993; Maher and Thompson 1995; Porter et al. 2001; Shen et al. 1992), and have used this fact in various approaches to deduce records of paleoprecipitation or geomagnetic variability. In one instance (Maher and Thompson 1995), the correlation between modern rainfall and total magnetic susceptibility in surficial loess/paleosols was used to derive a paleoprecipitation record. The chief difficulty with this method is in first constraining the effects of recycled dust on magnetic susceptibility. In a second approach (Porter et al. 2001), an attempt to remove the dust component of magnetic susceptibility is first made using a grain size model, then the residual susceptibility is correlated to modern precipitation patterns. In a third method, Beer et al. (1993) and Heller et al. (1993) used loess ${ }^{10} \mathrm{Be}$ concentrations to first constrain and remove the fractions of magnetic susceptibility associated with recycled dust in surface loess/ paleosols, then they correlate the residual signal with modern precipitation for various regions of the loess plateau to establish a modern calibration, which they then use to reconstruct paleoprecipitation. While this last technique does remove the component of susceptibility associated with inherited dust, it does not account for variations in the ${ }^{10} \mathrm{Be}$ signal associated with geomagnetic modulation of ${ }^{10} \mathrm{Be}$, which accounts for nearly half of the total ${ }^{10} \mathrm{Be}$ signal.

In our method, we modify these approaches by first removing the inherited dust signal from both magnetic susceptibility and ${ }^{10} \mathrm{Be}$ concentration records, then we extract the rainfall effect using the correlation between the inherited-dust-free ${ }^{10} \mathrm{Be}$ and magnetic susceptibility fractions. The residual

${ }^{10} \mathrm{Be}$ signal is then converted to a flux using the sediment accumulation rate, divided by the range in flux, and then normalized to the modern production flux. This signal is then used to provide a record of geomagnetic fluctuations using the production rate dependence on magnetic field intensity (Masarik and Beer 1999). Once the time function describing the variations in ${ }^{10} \mathrm{Be}$ flux due to geomagnetic-field fluctuations is established, we solve for the variations in ${ }^{10} \mathrm{Be}$ flux due to changes in precipitation by dividing the dust-free ${ }^{10} \mathrm{Be}$ fluxes by the geomagnetic-field production-rate modulation function to obtain a record of variations in ${ }^{10} \mathrm{Be}$ flux due to changes in wet precipitation. Finally, we use the correlation between ${ }^{7} \mathrm{Be}$ in modern precipitation (Caillet et al. 2001; Ishikawa et al. 1995; Wallbrink and Murray 1994) and tropospheric ${ }^{10} \mathrm{Be} /{ }^{7} \mathrm{Be}$ ratio to derive quantitative estimates of paleoprecipitation.

\section{METHODS}

\section{Sampling and Measurements}

Analyses were performed on a 970-cm-long core taken from the Luochuan loess section in central China $\left(35^{\circ} 45^{\prime} \mathrm{N}, 109^{\circ} 25^{\prime} \mathrm{E}\right)$ (Figure 1 ). This core was sampled at approximately 100 -yr intervals $(1 \mathrm{~cm})$ for grain size analysis, dry bulk density, and magnetic susceptibility measurements at the Xi' an Laboratory of Loess and Quaternary Geology (Figure 2 and Appendix: Table 2). The core was sampled at $4-\mathrm{cm}$ intervals for ${ }^{10} \mathrm{Be}$ measurements, except during the interval representing the last 
glacial maximum (LGM), where it was sampled at 1-cm intervals. Additional details on sampling methodology are given in the Appendix. The $247 \mathrm{BeO}$ samples were chemically prepared at the Xi' an Laboratory of Loess and Quaternary Geology. The majority of these samples were measured for ${ }^{10} \mathrm{Be}$ on the 3MV accelerator mass spectrometer of VERA (Vienna Environmental Research Accelerator) at the University of Vienna (Priller et al. 2000). Approximately $20 \%$ of the ${ }^{10} \mathrm{Be}$ analyses were made on the $3 \mathrm{MV}$ accelerator mass spectrometer at the NSF-Arizona AMS Facility at the University of Arizona. All ${ }^{10} \mathrm{Be}$ concentrations have been corrected for radioactive decay (Appendix: Table 2). ${ }^{10} \mathrm{Be}$ AMS measurements at both VERA and Arizona were made at $3 \mathrm{MV}$ accelerating voltage using 1-3 uA ${ }^{9} \mathrm{Be}^{16} \mathrm{O}^{-}$target injection currents. VERA used gas stripping in the terminal to $3+$ for high-energy analysis, whereas Arizona used gas stripping to $2+$ in the terminal and then foil stripping of the ions to $3+$ after high-energy magnetic and electrostatic separation at 2+, but prior to analysis through a second 1.2-m-radius electrostatic analyzer (ESA) and switching magnet. Both labs used a 2-stage $\mathrm{dE}-\mathrm{dx}$ coincidence gas analyzer in which the interfering isobar ${ }^{10} \mathrm{~B}$ is completely stopped in the first stage. These analysis techniques are described in greater detail in Priller et al. (2004) (VERA) and McHargue et al. (2000) (Arizona).

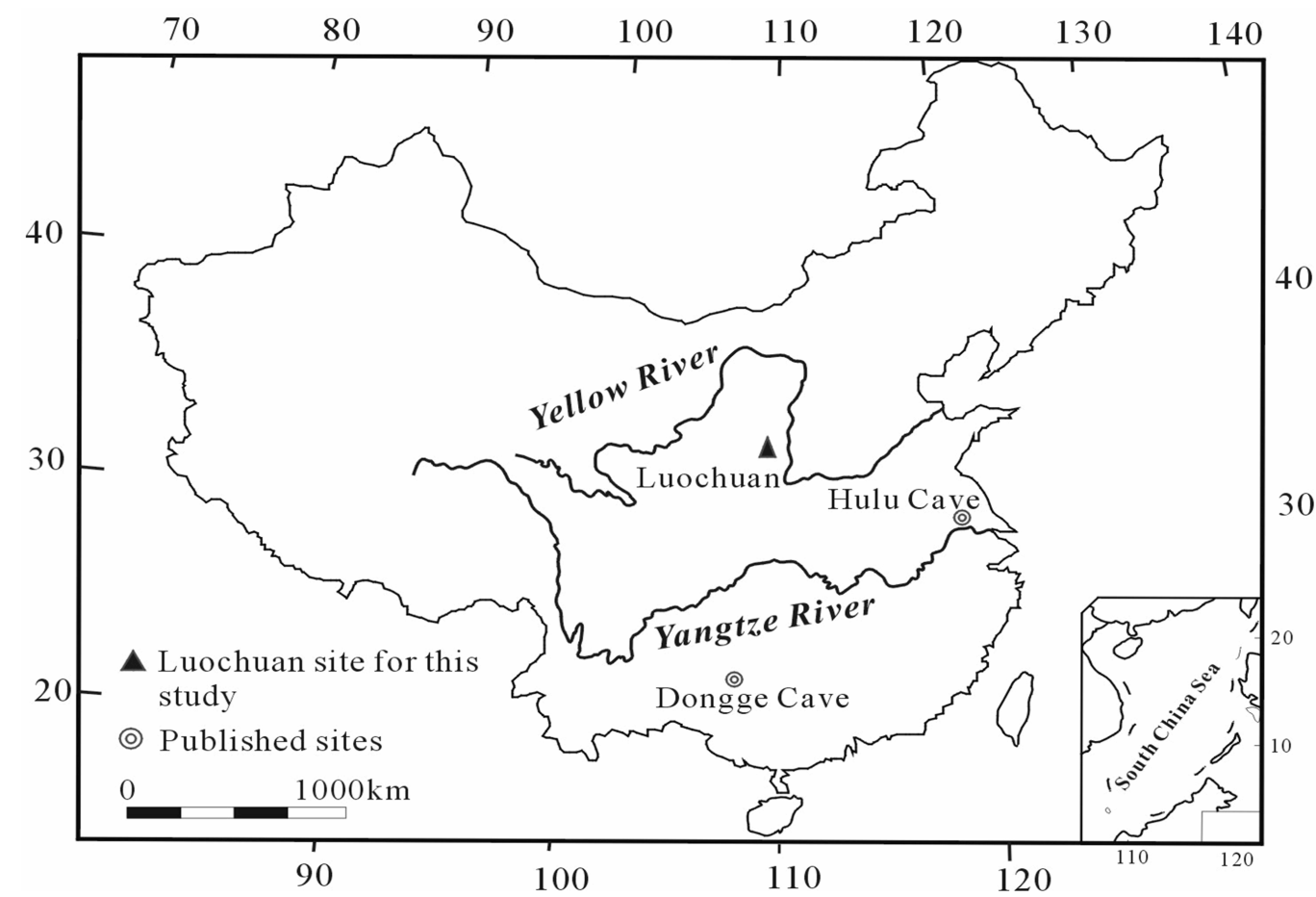

Figure 1 Map showing the location of Luochuan where the sample core was taken, in the context of the regional setting of the Chinese Loess Plateau. Also shown are the locations of Hulu Cave and Dongge Cave, from which $\delta^{18} \mathrm{O}$ records representing the East Asian Monsoon intensity were used for comparison with the paleoprecipitation reconstruction from Luochuan.

\section{Time Scale}

A calendar age model for this loess sequence was generated using a grain size vs. accumulation rate model (Porter and An 1995; Wu 2004). This calendar age scale was then compared to a combination of optical luminescence (OSL) and ${ }^{14} \mathrm{C}$ ages for the younger portion of this time scale (Figure 2 and 

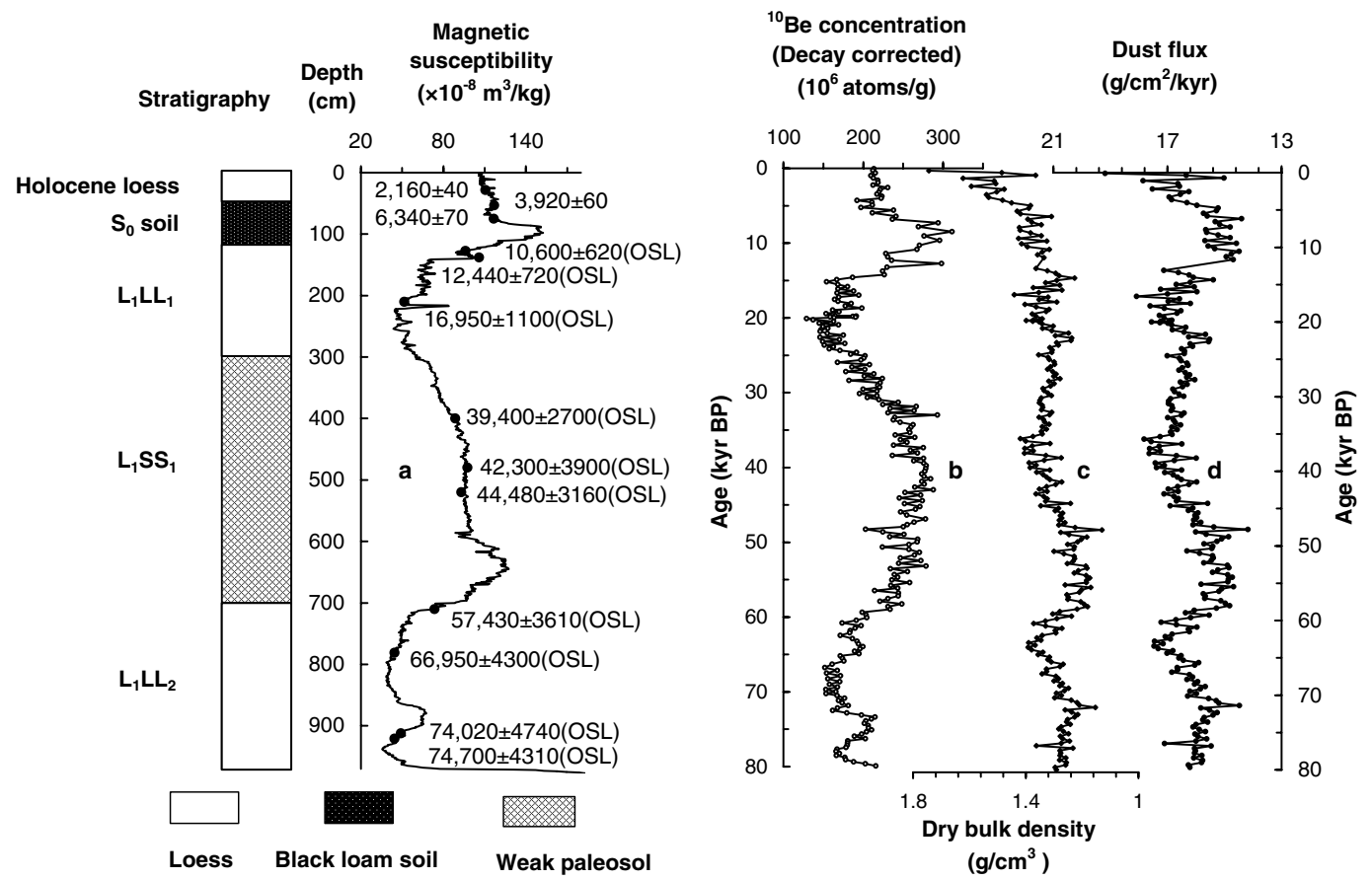

Figure 2 Loess magnetic and ${ }^{10} \mathrm{Be}$ stratigraphy at Luochuan, China $\left(35^{\circ} 45^{\prime} \mathrm{N}, 109^{\circ} 25^{\prime} \mathrm{E}\right)$. Shown from left to right: loess/ paleosol stratigraphy; sample depths; magnetic susceptibility (magnetic dipole moment/unit volume in SI units) with locations of OSL and ${ }^{14} \mathrm{C}$ dates superimposed (black dots); uncalibrated ages (kyr BP) (calibrated ages listed in Appendix: Table 3); ${ }^{10} \mathrm{Be}$ concentration $\left(10^{6}\right.$ atoms $\left./ \mathrm{g}\right)$; dry bulk density; and dust flux $\left(\mathrm{g} / \mathrm{cm}^{2} / \mathrm{kyr} \mathrm{BP}\right)$. Dust flux is calculated from the age model and dry bulk density data (see Appendix).

Appendix: Tables 3,4). For the older portion of the record, we cross-checked the age model using a correlation (Porter 2001) between the magnetic susceptibility (SUS) curve from the loess sequence with the SPECMAP marine oxygen isotope (MIS) curve, and using inferred L1/S0 (Gu et al. 1996) (12.3 kyr BP) and S1/L1 (GRIP ${ }^{18} \mathrm{O}$ age $79 \pm 1 \mathrm{kyr}$ BP [Johnsen et al. 2001]) stratigraphic boundaries (Liu and Ding 1998), which correlate with MIS 2/1 and 5/4 transitions (Porter and An 1995). The calendar ages provided by this grain size model were found to be in good agreement with these external cross-checks.

\section{RESULTS AND DISCUSSION}

\section{Geomagnetic Field Intensity Deconvolution}

To isolate the ${ }^{10} \mathrm{Be}$ component associated with reworked dust, we first define the measured magnetic susceptibility (SUS(M)) as the sum of 2 components, SUS(D) and SUS(P), of which the former is the inherited dust-borne fraction of SUS and the latter is pedogenic fraction of SUS, which is acquired through secondary mineral reactions after deposition of the loess, respectively (see Table 1 for a summary of term definitions).

To solve for SUS(D), we note that a comparison of loess magnetic susceptibility versus coercivity (Evans and Heller 2001) from a wide range of locations on the Loess Plateau for the last $135 \mathrm{kyr}$ reveals a pattern suggestive of 2-component mixing between a low-SUS/high-coercivity inheriteddust component, with admixtures of high-SUS/low-coercivity magnetic domains associated with 
Table 1 Definition of terms used in this paper.

\begin{tabular}{ll}
\hline Terms & Explanation \\
\hline $\mathrm{Be}(\mathrm{M})$ & The measured adsorbed ${ }^{10} \mathrm{Be}$ concentration in loess corrected for radioactive decay. \\
$\mathrm{Be}(\mathrm{D})$ & The concentration of recycled ${ }^{10} \mathrm{Be}$ adsorbed on remobilized dust. \\
$\mathrm{Be}(\mathrm{P}, \mathrm{GM})$ & $\begin{array}{l}\text { Equal to } \mathrm{Be}(\mathrm{M})-\mathrm{Be}(\mathrm{D}) . \text { Equivalent to the }{ }^{10} \mathrm{Be} \text { concentration in loess coming from } \\
\text { atmospheric fallout recently produced in the atmosphere by cosmic rays. }\end{array}$ \\
SUS(M) & The measured magnetic susceptibility. \\
SUS(D) & The fraction of SUS(M) inherited from recycled dust. \\
SUS(P) & $\begin{array}{l}\text { Equal to SUS(M) }-\mathrm{SUS}(\mathrm{D}) \text {. Equivalent to the pedogenic fraction of SUS(M), which } \\
\text { is acquired through secondary mineral reactions after deposition of the loess. }\end{array}$ \\
$\operatorname{Be}(\mathrm{GM})$ & $\begin{array}{l}\text { That fraction of the Be(P,GM) concentration signal that is due to fluctuations in the } \\
\text { geomagnetic field, as opposed to variations in wet precipitation. }\end{array}$ \\
\hline
\end{tabular}

pedogenesis (Figure 3 ). These data asymptotically approach a well-defined susceptibility value of $(25 \pm 3.5) \times 10^{-8}(1 \sigma) \mathrm{m}^{3} / \mathrm{kg}$ for the high-coercivity endmember (Evans and Heller 2001). In accord with the proposal made by these authors that this endmember represents a dry dust component of the loess susceptibility, samples at this end of the mixing curve corresponds to those from the driest periods, typical of the last glacial maximum (LGM) and marine isotope stage 4 (MIS4) when rainfall was thought to be very low in this region and pedogenesis was very slow. The fact that samples close to this endmember come from a wide geographic distribution from both the western and central Loess Plateau suggests that this dust endmember is spatially homogeneous with regards to susceptibility (Evans and Heller 2001). Recalling that susceptibility does not depend on dust flux rate but rather only on the concentration of magnetic domains and their size distribution, Evans and Heller (2001) found that for the most weakly weathered loess (which they identify as being from the driest periods), the mass fraction of hematite, magnetite, and maghemite were on average $0.9 \%$, $0.02 \%$, and $0.02 \%$, respectively, and that these concentrations are quite uniform over the geographic extent of the Chinese Loess Plateau. Furthermore, long records from the Loess Plateau show that loess magnetic susceptibility has been similar for each dry climate phase during the last $1 \mathrm{Myr}$ (Evans and Heller 2001). We use these arguments collectively to contend that there is a dry dust endmember component of SUS in the loess that is spatially and temporally homogeneous with a welldefined susceptibility value on a plot of coercivity versus susceptibility. We define a value for this SUS(D) component as the high-coercivity asymptotic endmember on this plot, yielding a value of $\operatorname{SUS}(D)=(25 \pm 3.5) \times 10^{-8}(1 \sigma) \mathrm{m}^{3} / \mathrm{kg}$. We then solve for SUS(P) for all times from the difference between SUS(D) and measured SUS(M) (Figure 4a).

Next, to solve for $\mathrm{Be}(\mathrm{D})$ (the adsorbed ${ }^{10} \mathrm{Be}$ concentration associated with remobilized dust), we define the total measured ${ }^{10} \mathrm{Be}$ concentration in the loess $(\mathrm{Be}(\mathrm{M}))$ as the sum of 2 sources: $\mathrm{Be}(\mathrm{D})$, which is ${ }^{10} \mathrm{Be}$ from atmospheric fallout produced at some time in the past, which was then adsorbed on dust, buried, and later remobilized; and $\mathrm{Be}(\mathrm{P}, \mathrm{GM})$, which is ${ }^{10} \mathrm{Be}$ fallout recently produced in the atmosphere by cosmic rays (modulated by the geomagnetic field intensity) and brought to the ground primarily by wet precipitation. We argue that $\mathrm{Be}(\mathrm{D})$ (i.e. the adsorbed ${ }^{10} \mathrm{Be}$ concentration in dust, not the ${ }^{10} \mathrm{Be}$ dust flux) should be highly uniform, because the dust falling on the Loess Plateau has been derived from a very large area (e.g. the Gobi and Taklimakin deserts and Loess Plateau) representing landscapes of many ages, and transported by a variety of aeolian processes over large distances during which substantial mixing occurs. 


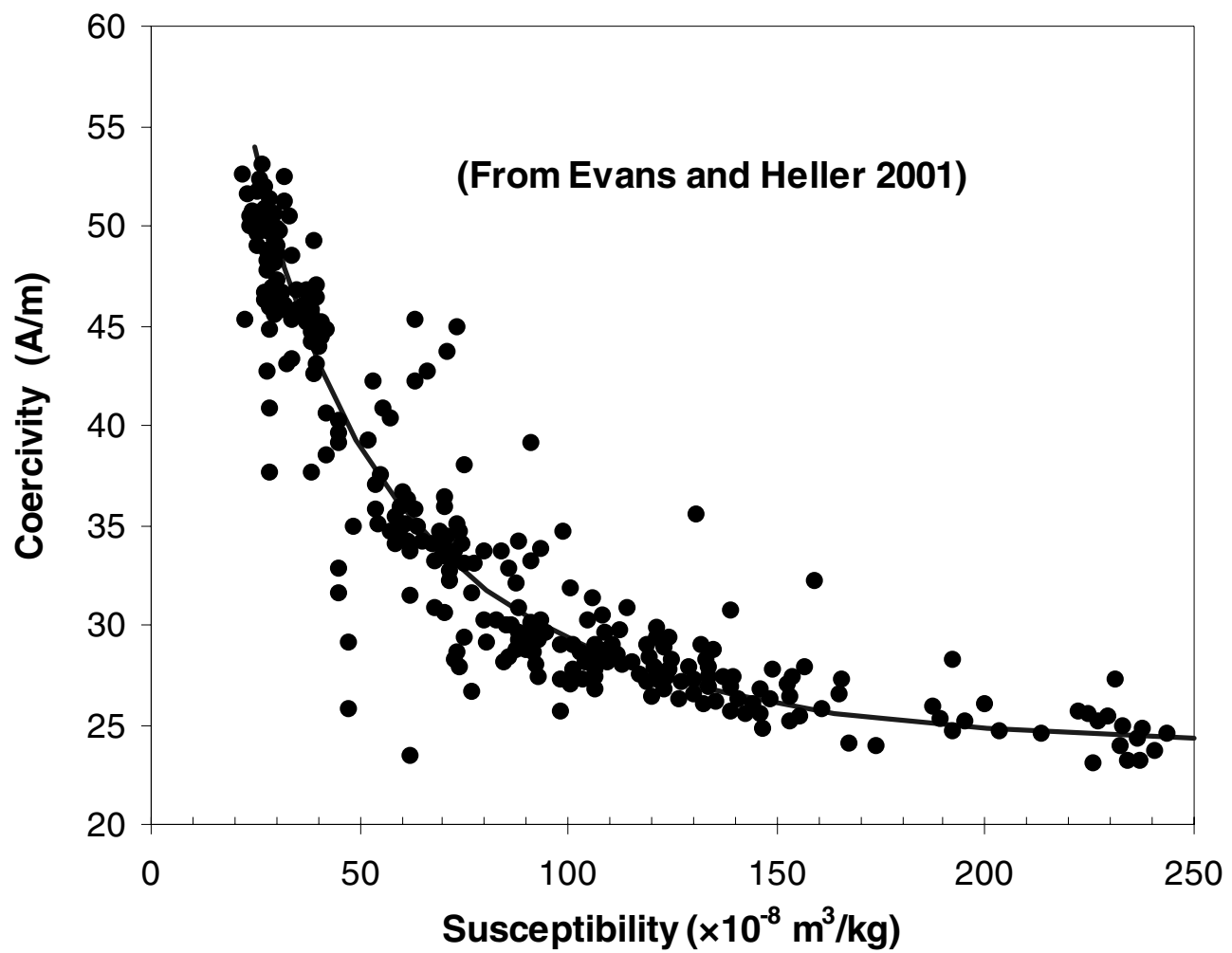

Figure 3 Loess magnetic susceptibility versus coercivity for samples from the western and central Chinese Loess Plateau. Note that the data array is suggestive of 2-component mixing between a low-susceptibility/high-coercivity recycled dust component, with admixtures of high-susceptibility/low-coercivity mineral grains added by pedogenesis of the loess during wetter epochs. We define a susceptibility value for the (dry) dust endmember component $(\mathrm{SUS}(\mathrm{D}))$ as the high-coercivity asymptotic endmember on this plot, yielding a value of $\mathrm{SUS}(\mathrm{D})=25 \pm 3.5(1 \sigma)$. Reprinted from Evans and Heller (2001), with additional thanks to Elsevier for copyright permission.

As in the case for susceptibility, we expect that during extremely dry periods, loess ${ }^{10} \mathrm{Be}$ concentration is dominated by the remobilized dust fraction $\mathrm{Be}(\mathrm{D})$, because nearly all $(>90 \%)$ atmospheric fallout of new ${ }^{10} \mathrm{Be}$ recently generated by cosmic-ray interactions results via wet precipitation (Wallbrink and Murray 1994). We show that SUS(M) and Be(M) are highly linearly correlated (Figure $4 \mathrm{~b})$. We determine the dry dust endmember $\mathrm{Be}(\mathrm{D})$ by using this correlation and the previous observation that $\operatorname{SUS}(\mathrm{D})=25 \times 10^{-8} \mathrm{~m}^{3} / \mathrm{kg}$. This yields a value of $\mathrm{Be}(\mathrm{D})=(136.4 \pm 6.25) \times 10^{6}(1 \mathrm{\sigma})$ atoms/g. As we already showed for SUS(P), we solve for Be(P,GM) by calculating the difference between $\mathrm{Be}(\mathrm{M})$ and $\mathrm{Be}(\mathrm{D})$ for the entire record (Figure $4 \mathrm{c}$ ).

After subtracting the effects of reworked dust, we observe that both $\mathrm{SUS}(\mathrm{P})$ and $\mathrm{Be}(\mathrm{P}, \mathrm{GM})$ form a linear array (Figure 4d). We assert that this linear correlation is due to the effect of variations in wet precipitation rate on the fallout flux of ${ }^{10} \mathrm{Be}$ on the one hand, and on the growth rate of pedogenic magnetic domains in the loess on the other hand. This linear relationship has a correlation coefficient of 0.81 , which indicates there is some other source of variance. We believe that much of this dispersion is due to the fact that $\mathrm{Be}(\mathrm{P}, \mathrm{GM})$ is also a function of geomagnetic field intensity in addition to the wet precipitation rate. Since it is likely that the variance associated with geomagnetic field variations is independent of climate, we may then remove the precipitation effect from 

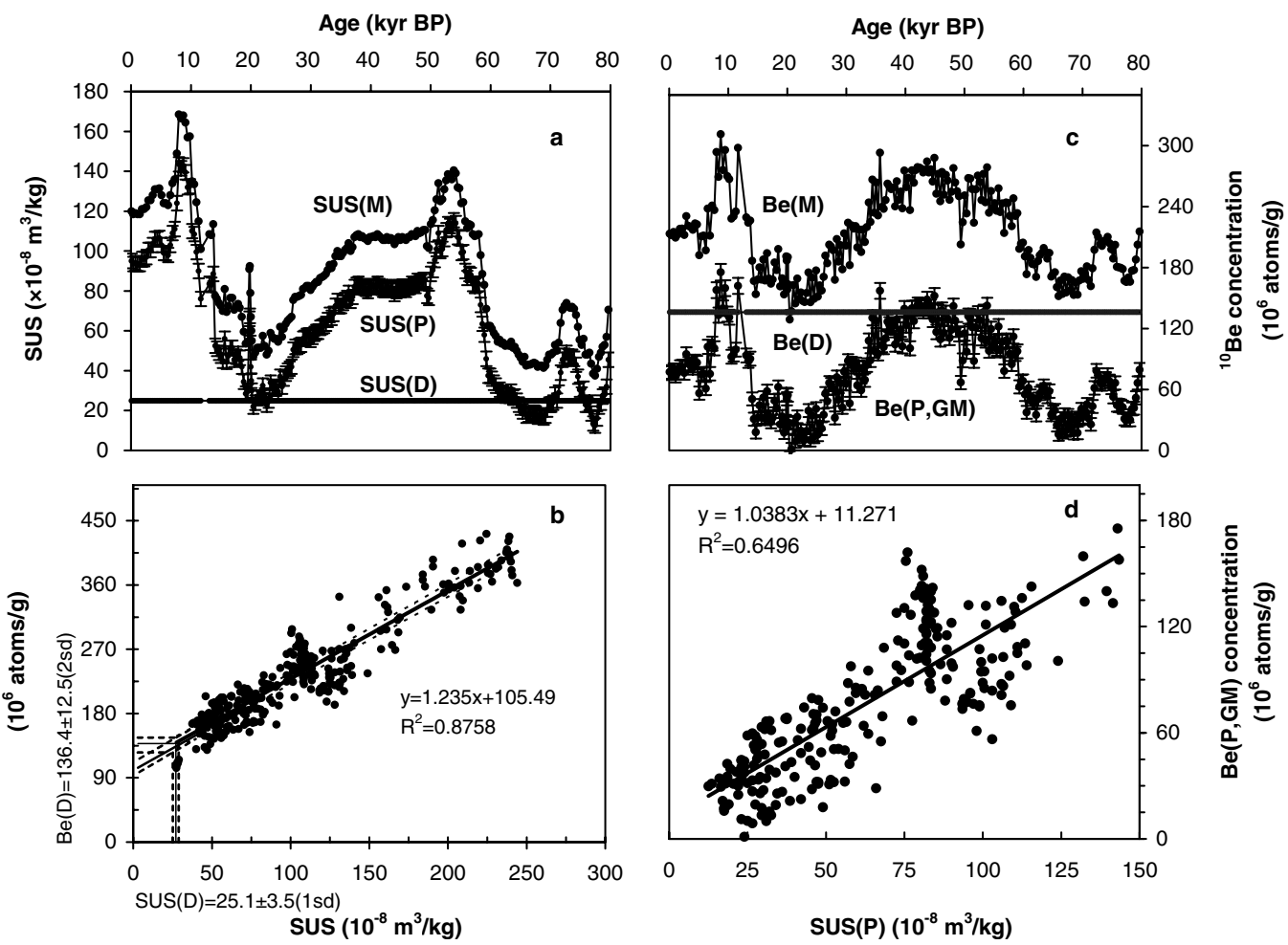

Figure 4 Deconvolution of loess magnetic susceptibility and ${ }^{10} \mathrm{Be}$ records. a) Measured magnetic susceptibility (SUS(M)) vs. time, decomposed into SUS(D) (dust) and SUS(P) (pedogenic) fractions. b) Measured magnetic susceptibility (SUS(M)) vs. measured ${ }^{10} \mathrm{Be}$ concentration $(\mathrm{Be}(\mathrm{M}))$. $\mathrm{Be}(\mathrm{D})$ is derived from this plot, from the coincidence of SUS(D) with the model linear regression through the data. The uncertainty in $\operatorname{Be}(\mathrm{D})$ is derived graphically from the intersection of the $(2 \sigma)$ uncertainty envelope around the regression with the (1 $\sigma)$ errors on SUS(D) determined from regression analysis of Figure 3. c) $\mathrm{Be}(\mathrm{M})$ vs. time decomposed into $\mathrm{Be}(\mathrm{D})$ and $\mathrm{Be}(\mathrm{P}, \mathrm{GM})$ (associated with atmospheric fallout and modulated by rainfall and geomagnetic field strength). d) Linear correlation between SUS(P) and Be(P,GM). This correlation defines the fraction of variance associated with the wet precipitation amount effect. Deviation from this line for each datum defines the residual variance assumed to be associated with geomagnetic modulation.

$\mathrm{Be}(\mathrm{P}, \mathrm{GM})$ using the correlation between $\mathrm{SUS}(\mathrm{P})$ and $\mathrm{Be}(\mathrm{P}, \mathrm{GM})$. After removal of the precipitation effect by subtraction of this linear correlation, the residual variations in $\mathrm{Be}(\mathrm{P}, \mathrm{GM})$ (i.e. $\mathrm{Be}(\mathrm{GM})$ ) due to geomagnetic modulation are revealed (not shown). Finally, we convert these residual $\mathrm{Be}(\mathrm{GM})$ concentration variances to flux using sediment accumulation rates, normalize them by dividing by the range, then scale them to the modern production rate (Masarik and Beer 1999), yielding a curve of ${ }^{10} \mathrm{Be}$ production rate relative to today (Figure $5 \mathrm{a}$ ).

\section{Reconstructed Magnetic Field Record}

Figure $5 \mathrm{a}$ shows the record of relative variations in ${ }^{10} \mathrm{Be}$ production rate for the last $80 \mathrm{kyr} \mathrm{BP}$, which we derived above. In Figure 5b, we convert this ${ }^{10} \mathrm{Be}$ production rate record to paleomagnetic field intensity (Masarik and Beer 1999), with the tacit assumption that solar modulation of ${ }^{10} \mathrm{Be}$ production rate is small relative to geomagnetic modulation at least for long period fluctuations. This plot shows that the low-frequency features of our paleomagnetic intensity record compare favorably with the SINT200 composite reconstruction (Guyodo and Valet 1996) (Figure 5b). These same broad features are also observed in the NAPIS 75 record (Laj et al. 2002), though its features are offset because 


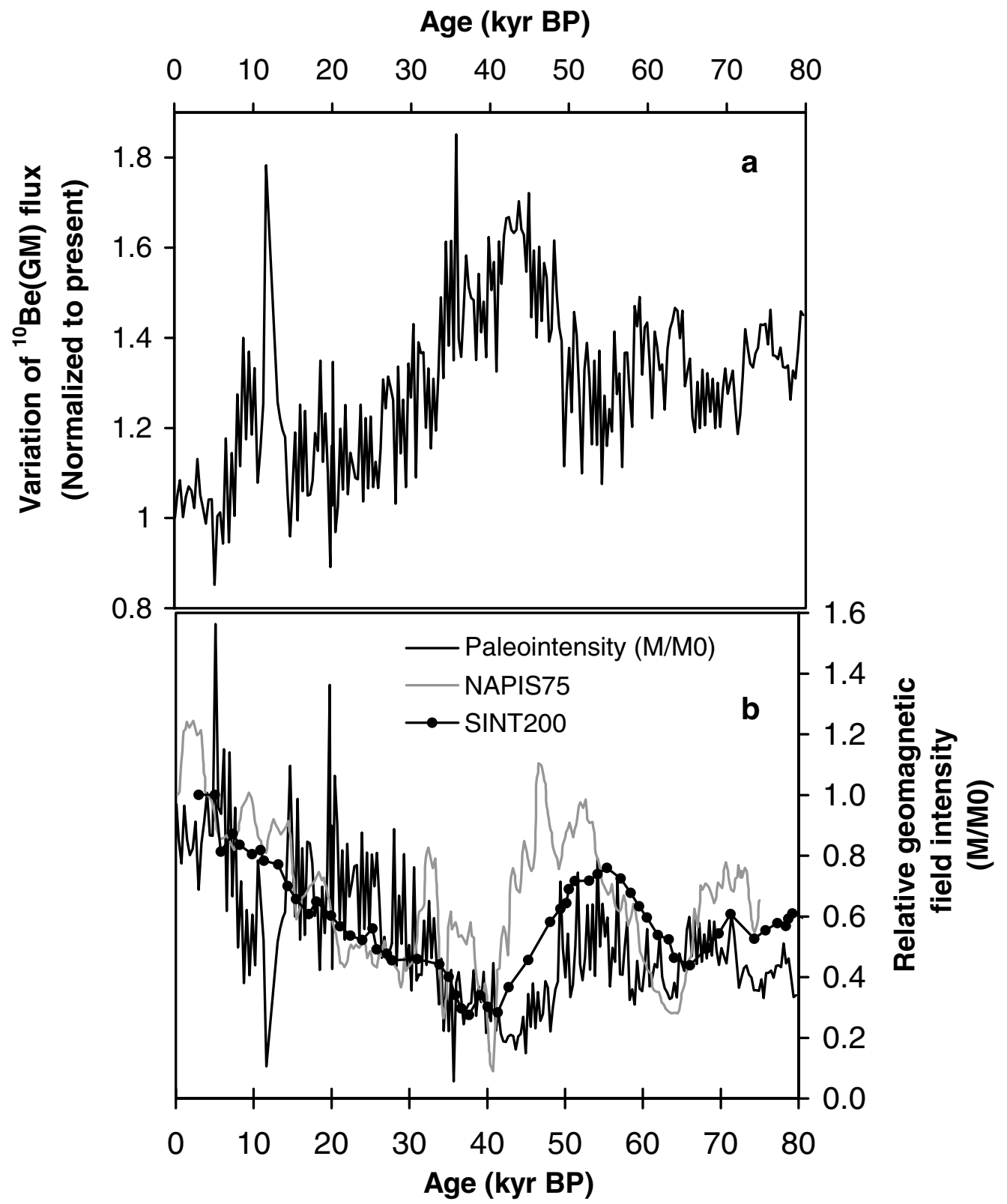

Figure 5 Deconvoluted ${ }^{10} \mathrm{Be}$ production rate variations and magnetic field variations. a) Loess-based ${ }^{10} \mathrm{Be}$ production rates normalized to the modern rate, after removal of the reworked dust signal and variations due to changes in wet precipitation. The data are presented as ${ }^{10} \mathrm{Be}$ flux, using sediment accumulation rate to convert from concentration. $\mathrm{b}$ ) Inferred variations in geomagnetic field (black) normalized to the modern field, compared to the composite records NAPIS75 (Laj et al. 2002) (gray) and SINT200 (Guyodo and Valet 1996) (black with dots). Our magnetic field record was derived from inversion of the ${ }^{10} \mathrm{Be}$ production rate record shown in (a), using the model provided by Masarik and Beer (1999), and the assumption that all fluctuations in production rate are due to changes in geomagnetic field. As discussed in the Appendix in "Propagation of Errors," mean uncertainty in calculated M/Mo is $21 \%$. 
it utilizes a different calendar age model. Our record clearly shows the Laschamp geomagnetic minima events at about $42 \mathrm{kyr}$ BP, as well as a smaller local minima at about 60-65 kyr BP, and geomagnetic maxima at about 55 and $70 \mathrm{kyr}$ BP observed in these 2 composite records. The long rise in geomagnetic intensity common to most records observed between about 40 and $5 \mathrm{kyr} \mathrm{BP}$ is also observed in our record, as is an abrupt drop in intensity (reflected by an increased ${ }^{10} \mathrm{Be}$ flux in Figure 1a) at about $33 \mathrm{kyr}$ BP, which we tentatively assign to the Mono Lake event (Wagner et al. 2000). There is also a prominent late Holocene paleomagnetic maximum similar to that seen in archaeomagnetic records (Yang et al. 2000), though in our record this maxima occurs $\sim 1-2 \mathrm{kyr}$ earlier.

One feature found in our record not expressed in either the SINT200 or NAPIS75 records is a period of apparently enhanced ${ }^{10} \mathrm{Be}$ concentration between about 15.5 and $8 \mathrm{kyr}$ BP. If this feature were due to increased ${ }^{10} \mathrm{Be}$ production rate, we might expect a similar anomaly in the record of atmospheric ${ }^{14} \mathrm{C}$ (Reimer et al. 2005). However, while atmospheric ${ }^{14} \mathrm{C}$ concentrations were indeed significantly increased during the Younger Dryas-Bølling-Allerød part of this time frame (13.8 and $11.3 \mathrm{kyr}$; Hughen et al. 2004), this period of elevated ${ }^{14} \mathrm{C}$ is much shorter in duration than is seen in our loess record. This suggests that there may still be climatic influences in this record that we have failed to isolate. Nevertheless, the strong similarity among SINT 200, NAPIS 75, and the long wavelength features of our paleomagnetic intensity record suggests that this method of generating paleomagnetic intensity records is generally robust. If so, this technique could be used to generate an extremely long-term high-resolution record of paleomagnetic field intensity since the loess record extends back about 2.6 Myr BP, and this is less than just 2 half-lives of ${ }^{10} \mathrm{Be}$.

\section{Paleoprecipitation Reconstruction}

We also can generate a paleoprecipitation record by beginning with $\mathrm{Be}(\mathrm{P}, \mathrm{GM})$, i.e. the inheriteddust-free concentration of ${ }^{10} \mathrm{Be}$ signal in loess, as derived above. We recall that $\mathrm{Be}(\mathrm{P}, \mathrm{GM})$ varies in response to the product of the wet precipitation amount and the ${ }^{10} \mathrm{Be}$ production rate (modulated by geomagnetic field). We first convert $\mathrm{Be}(\mathrm{P}, \mathrm{GM})$ to a ${ }^{10} \mathrm{Be}$ flux by multiplying $\mathrm{Be}(\mathrm{P}, \mathrm{GM})$ by the loess accumulation rate (derived from the age model), then we remove the variations in $\mathrm{Be}(\mathrm{P}, \mathrm{GM})_{\mathrm{flux}}$ due to geomagnetic modulation by dividing $\mathrm{Be}(\mathrm{P}, \mathrm{GM})_{\text {flux }}$ by the geomagnetic modulation function derived above from subtraction of the cross-correlation between SUS(P) and Be(P,GM). This removes flux variations that are due to magnetic field fluctuations. The residual variations in ${ }^{10} \mathrm{Be}$ flux (i.e. $\mathrm{Be}(\mathrm{P})_{\text {flux }}$ ) are then considered to be due to fluctuations in wet precipitation.

We derive quantitative estimates of paleoprecipitation from this residual signal using ${ }^{7} \mathrm{Be}$ as an analogue for ${ }^{10} \mathrm{Be}$, and using the relationship between ${ }^{7} \mathrm{Be}$ concentration and precipitation amount in modern rainfall. While ${ }^{7} \mathrm{Be}$ has a similar atmospheric production pathway to ${ }^{10} \mathrm{Be}$, its very short half-life means that there is no recycled dust component to confuse its relationship with rainfall amount. In 3 different ${ }^{7} \mathrm{Be}$ vs. precipitation amount studies on 3 continents (Caillet et al. 2001; Ishikawa et al. 1995; Wallbrink and Murray 1994), a similar linear relationship is found. Using the average slope in these studies, we then convert from ${ }^{7} \mathrm{Be}$ to ${ }^{10} \mathrm{Be}$ using the known ${ }^{10} \mathrm{Be} /{ }^{7} \mathrm{Be}$ flux ratio in modern tropospheric precipitation (Priller et al. 2004). We use the slope of this resulting ${ }^{10} \mathrm{Be}$ vs. precipitation line to calculate precipitation amounts, but we first adjust the intercept (corresponding to the local dry fallout fraction) to match the ${ }^{10} \mathrm{Be}$ flux vs. precipitation observed at Luochuan today. In this way, a precipitation record can be extracted from $\mathrm{Be}(\mathrm{P})_{\mathrm{flux}}$, which accounts for both wet and dry fallout fractions.

Figure 6 shows the resulting paleoprecipitation record that we have derived from the loess ${ }^{10} \mathrm{Be}$ record after removal of the dust and geomagnetic modulation influences. The general shape of this curve appears well correlated with the speleothem $\delta^{18} \mathrm{O}$ records from Dongge (Yuan et al. 2004) and 
Hulu (Wang et al. 2001) caves in SE China, which are widely regarded as a robust record of Asian Monsoon intensity (Figure 6a). Our record indicates extremely low rainfall for the LGM and marine isotope stage 4 (MIS4), with precipitation rising gradually out of MIS4 to near-modern levels during MIS3. After about $35 \mathrm{kyr}$ BP, precipitation began a long decline culminating in a 5-kyr-long minima during the LGM ending at about $20 \mathrm{kyr}$ BP. Precipitation then increased stepwise in dramatic fashion at $\sim 20 \mathrm{kyr}$, and again at $14.3 \mathrm{kyr}$. Precipitation was constant or decreased slightly between 13 and $11 \mathrm{kyr}$, followed by another abrupt precipitation increase culminating in a Holocene maximum at 9 kyr BP. Precipitation then dropped rapidly to a Holocene minimum at $5.8 \mathrm{kyr}$ BP, followed by a modest rise to $4 \mathrm{kyr}$, then a gentle decay and another small rise to the present during the late Holocene.

While our precipitation record is broadly similar in shape to the Dongge and Hulu $\delta^{18} \mathrm{O}$ records, there are some surprising differences. Both records show large millennial-scale fluctuations during the deglacial and Holocene; however, during MIS3 these are significantly damped in our record relative to that seen in the Dongge/Hulu $\delta^{18} \mathrm{O}$ records. This is surprising considering that today, Luochuan is located near the northern boundary of SE Asian Monsoon influence, in a region of high rainfall gradient. Consequently, we had expected to see even higher sensitivity to variations in summer monsoon intensity at Luochuan than at Hulu or Dongge, which lie $\sim 1000 \mathrm{~km}$ to the east and south, respectively. One could explain this observation if our record were smoothed at millennial scales by some geologic process such as post-depositional wind mobilization of fallout ${ }^{10} \mathrm{Be}$.

Some large millennial-scale fluctuations are observed in our record, such as that seen at about $48 \mathrm{kyr}$ $\mathrm{BP}$ - potentially linked with Heinrich event H5. Several other abrupt changes are seen during the deglacial, and abrupt drops in precipitation are also seen at about 28 and $35 \mathrm{kyr}$ BP, which could be correlative with $\mathrm{H} 3$ or H4. Of particular interest are the deglacial and Holocene changes, which express many similarities with the Dongge/Hulu records. Two large precipitation increases are observed that are roughly coeval with meltwater pulses 1 and 2, suggesting a coupling between high and low latitude climate dynamics during the deglacial (Zhou et al. 2001). It is interesting to note, however, that at Luochuan the $\sim 9 \mathrm{kyr}$ BP Holocene precipitation maximum peaks at the same time as the Dongge record, but falls off much more rapidly, reaching a minimum at about $5.8 \mathrm{kyr} \mathrm{BP}$, whereas Dongge continues to drop until $\sim 2 \mathrm{kyr}$ BP. This asynchronous behavior may be understood in terms of the penetration depth of summer monsoon moisture into the continental interior being linked to insolation-driven land-sea temperature differential (An et al. 2000).

Like the Dongge and Hulu records, the low-frequency component of our precipitation record resembles the summer (JJA) solar insolation curve for $30^{\circ} \mathrm{N}$, except during MIS3, when it more strongly resembles the insolation differential between $30^{\circ} \mathrm{N}$ and $30^{\circ} \mathrm{S}$ (Figure $6 \mathrm{~b}$ ). This can be understood in terms of two of the chief elements of monsoon forcing: 1) land/sea temperature differential and 2) the cross-hemispheric atmospheric pressure gradient exhibited over the tropical ocean (Clemens and Prell 2003). Land-sea differential is largely governed by sensible heating over the Asian continent during boreal summer, which is strongly influenced by snow cover over the Tibetan Plateau centered on $\sim 30^{\circ} \mathrm{N}$. Similarly, according to some estimates, $80-90 \%$ of the moisture flux in the Asian Monsoon originates from the southern subtropical Indian Ocean (Clemens et al. 1996). This flux is driven by the interhemispheric pressure gradient, which is coupled to the tropical interhemispheric insolation gradient. It is perhaps not surprising then that the paleo-Asian Monsoon intensity appears to be responding to some combination of both Northern and Southern Hemisphere insolation forcing. 

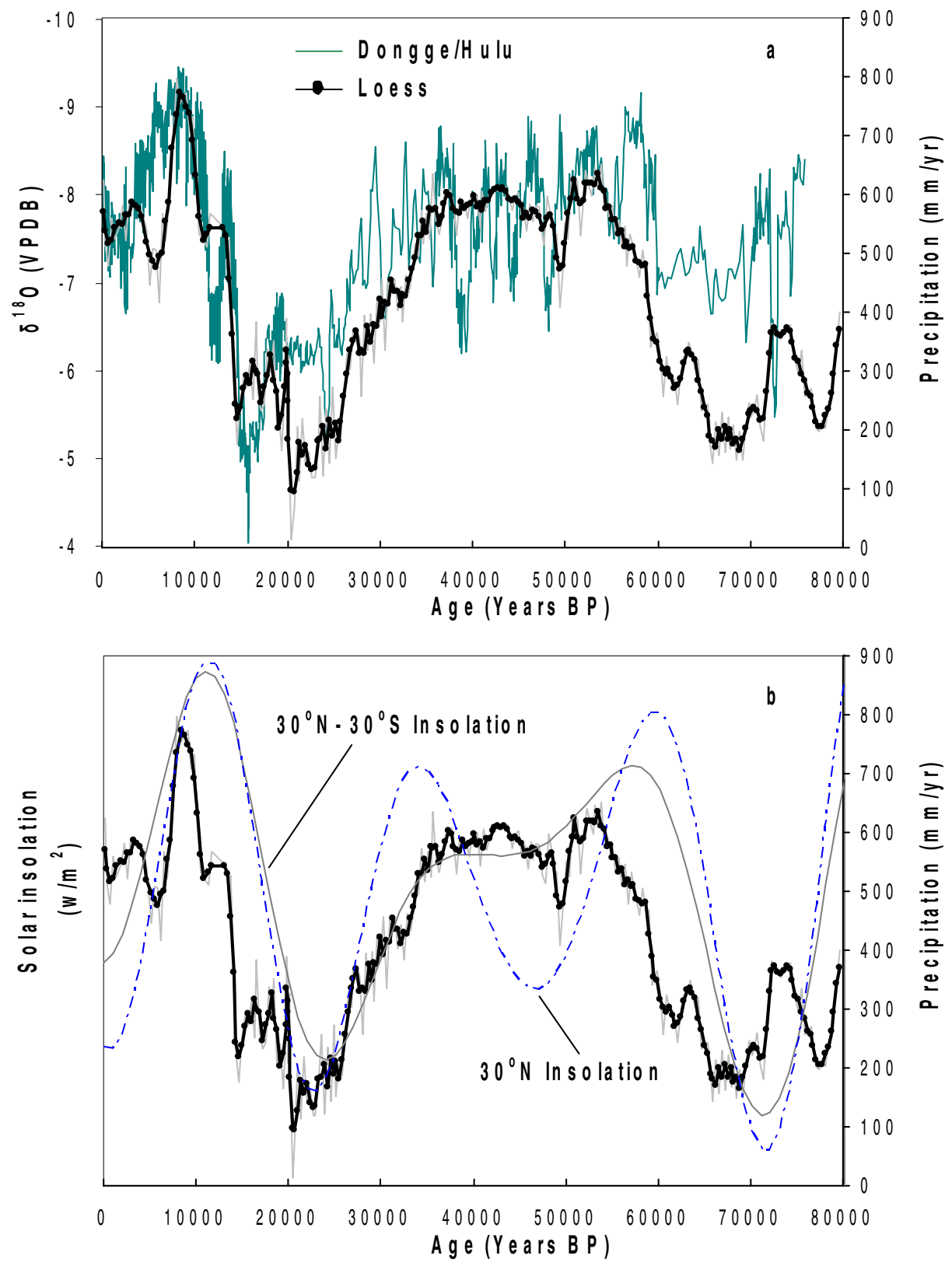

Figure 6 Paleoprecipitation reconstruction $(\mathrm{mm} / \mathrm{yr})$ derived from $\mathrm{Be}(\mathrm{P})$ after removal of the dust and geomagnetic modulation components of the ${ }^{10} \mathrm{Be}$ flux signal. a) Loess precipitation record is highly correlated with speleothem $\delta^{18} \mathrm{O}$ records from Dongge and Hulu caves (Wang et al. 2001; Yuan et al. 2004), which are thought to be representative of variations in the Asian Monsoon intensity. As discussed in the Appendix in "Propagation of Errors," the mean uncertainty in calculated annual precipitation is 19.5\%. b) Loess precipitation record compared to records of solar insolation (Berger and Loutre 1991). Like the Dongge and Hulu records, the low-frequency component of our precipitation record resembles the summer (JJA) solar insolation curve for $30^{\circ} \mathrm{N}$, except during MIS3, when it more strongly resembles the insolation differential between $30^{\circ} \mathrm{N}$ and $30^{\circ} \mathrm{S}$, suggesting that interhemispheric insolation gradient is also important in forcing the Asian Monsoon. 


\section{ACKNOWLEDGMENTS}

We gratefully acknowledge support for this work from the National Science Foundation of China, the Knowledge Innovation Program of the Chinese Academy of Sciences, the National Basic Research Program of China, and the United States National Science Foundation. Special thanks go to Dr Wang Xulong for providing the OSL dating, and to Dr Tim Jull and Dr Marc Caffee for helpful comments and clarifications of the manuscript.

\section{REFERENCES}

Aitken MJ. 1998. An Introduction to Optical Dating. London: Oxford University Press. 280 p.

An Z, Kukla GJ, Porter SC, Xiao J. 1991. Magnetic susceptibility evidence of monsoon variation on the Loess Plateau of central China during the last 130,000 years. Quaternary Research 36(1):29-36.

An Z, Porter SC, Kutzbach JE, Wu X, Wang S, Liu X, Li X, Zhou W. 2000. Asynchronous Holocene optimum of the East Asian Monsoon. Quaternary Science Reviews 19(8):743-62.

Beer J, Shen CD, Heller F, Liu TS, Bonani G, Dittrich B, Suter M, Kubik PW. 1993. ${ }^{10} \mathrm{Be}$ and magnetic susceptibility in Chinese loess. Geophysical Research Letters 20(1):57-60.

Beer J, Muscheler R, Wagner G, Laj C, Kissel C, Kubik PW, Synal H-A. 2002. Cosmogenic nuclides during Isotope Stages 2 and 3. Quaternary Science Reviews 21(10):1129-39.

Berger A, Loutre MF. 1991. Insolation values for the climate of the last 10 million years. Quaternary Science Reviews 10(4):297-317.

Bevington PR, Robinson DK. 1969. Data Reduction and Error Analysis for the Physical Sciences. New York: McGraw-Hill, Inc.

Bronk Ramsey C. 2001. Development of the radiocarbon calibration program. Radiocarbon 43(2A):355-63.

Caillet S, Arpagaus P, Monna F, Dominik J. 2001. Factors controlling ${ }^{7} \mathrm{Be}$ and ${ }^{210} \mathrm{~Pb}$ atmospheric deposition as revealed by sampling individual rain events in the region of Geneva, Switzerland. Journal of Environmental Radioactivity 53(2):241-56.

Clemens SC, Prell WL. 2003. A 350,000 year summermonsoon multi-proxy stack from the Owen Ridge, Northern Arabian Sea. Marine Geology 201(1-3):3551.

Clemens SC, Murray DW, Prell WL. 1996. Nonstationary phase of the Plio-Pleistocene Asian Monsoon. Science 274(5289):943-8.

Evans ME, Heller F. 2001. Magnetism of loess/palaeosol sequences: recent developments. Earth-Science Reviews 54(1-3):129-44.

Gu Z, Lal D, Southon J, Caffee MW, Guo ZT, Chen MY. 1996. Five million year ${ }^{10} \mathrm{Be}$ record in Chinese loess and red-clay: climate and weathering relationships. Earth and Planetary Science Letters 144(1-2):27387.

Guyodo Y, Valet J-P. 1996. Relative variations in geomagnetic intensity from sedimentary records: the past

200,000 years. Earth and Planetary Science Letters 143(1-4):23-36.

Heller F, Shen CD, Beer J, Liu XM, Liu TS, Bronger A, Suter M, Bonani G. 1993. Quantitative estimates of pedogenic ferromagnetic mineral formation in Chinese loess and palaeoclimatic implications. Earth and Planetary Science Letters 114(2-3):385-90.

Hughen K, Lehman S, Southon J, Overpeck J, Marchal O, Herring C, Turnbull J. 2004. ${ }^{14} \mathrm{C}$ activity and global carbon cycle changes over the past 50,000 years. $S c i$ ence 303(5655):202-7.

Ishikawa Y, Murakami H, Sekine T, Yoshihara K. 1995. Precipitation scavenging studies of radionuclides in air using cosmogenic ${ }^{7} \mathrm{Be}$. Journal of Environmental Radioactivity 26(1):19-36.

Jeter SM. 2003. Evaluating uncertainty of polynomial regression models using Excel. In: Proceedings of the 2003 American Society for Engineering Education Annual Conference \& Exposition. Nashville, USA: American Society for Engineering Education. p 9891007.

Johnsen SJ, Dahl-Jensen D, Gunderstrup N, Steffensen JP, Clausen HB, Miller H, Masson-Delmotte V, Sveinbjörnsdóttir AE, White J. 2001. Oxygen isotope and palaeotemperature records from six Greenland icecore stations: Camp Century, Dye-3, GRIP, GISP2, Renland and NorthGRIP. Journal of Quaternary Science 16(4):299-307.

Kukla G, An Z, Melice JL, Gavin J, Xiao JL. 1990. Magnetic susceptibility record of Chinese loess. Transactions of the Royal Society of Edinburgh, Earth Sciences 81:263-88.

Laj C, Kissel C, Mazaud A, Michel E, Muscheler R, Beer J. 2002. Geomagnetic field intensity, North Atlantic Deep Water circulation and atmospheric $\Delta^{14} \mathrm{C}$ during the last 50 kyr. Earth and Planetary Science Letters 200(1-2):177-90.

Liu T, Ding Z. 1998. Chinese loess and the paleomonsoon. Annual Review of Earth and Planetary Sciences 26:111-45.

Lu YC, Wang XL, Wintle AG. 2007. A new OSL chronology for dust accumulation in the last 130,000 years for the Chinese Loess Plateau. Quaternary Research 67(1):152-60.

Maher BA, Taylor RM. 1988. Formation of ultrafinegrained magnetite in soils. Nature 336(6197):368-70.

Maher BA, Thompson R. 1991. Mineral magnetic record of Chinese loess and paleosols. Geology 19(1):3-6. 
Maher BA, Thompson R. 1995. Paleorainfall reconstructions from pedogenic magnetic susceptibility variations in the Chinese loess and paleosols. Quaternary Research 44(3):383-91.

Masarik J, Beer J. 1999. Simulation of particle fluxes and cosmogenic nuclide production in the Earth's atmosphere. Journal of Geophysical Research 104(D10): 12,099-112.

McHargue LR, Donahue D, Damon PE, Sonett P, Biddulph D, Burr G. 2000. Geomagnetic modulation of the late Pleistocene cosmic-ray flux as determined by ${ }^{10} \mathrm{Be}$ from Blake Outer Ridge marine sediments. $\mathrm{Nu}$ clear Instruments and Methods in Physics Research B 172(1-4):555-61.

Pan Y, Zhu R, Shaw J, Liu Q, Guo B. 2001. Can relative paleointensities be determined from the normalized magnetization of the wind-blown loess of China? Journal of Geophysical Research 106(B9):19,221-32.

Porter SC. 2001. Chinese loess record of monsoon climate during the last glacial-interglacial cycle. EarthScience Reviews 54(1-3):115-28.

Porter SC, An Z. 1995. Correlation between climate events in the North Atlantic and China during the last glaciation. Nature 375(6529):305-8.

Porter SC, Hallet B, Wu X, An Z. 2001. Dependence of near-surface magnetic susceptibility on dust accumulation rate and precipitation on the Chinese Loess Plateau. Quaternary Research 55(3):271-83.

Priller A, Berger M, Gäggler HW, Gerasopoulos E, Kubik PW, Schnabel C, Tobler L, Wild E-M, Zanis P, Zerefos C. 2004. Accelerator mass spectrometry of particle-bound ${ }^{10} \mathrm{Be}$. Nuclear Instruments and Methods in Physics Research B 223-224:601-7.

Priller A, Brandl T, Gosler R, Kutchera W, Puchegger S, Rom W, Steier P, Vockenhuber C, Wallner A, Wild E. 2000. Extension of the measuring capabilities at VERA. Nuclear Instruments and Methods in Physics Research B 172(1-4):100-6.

Reimer PJ, Baillie MGL, Bard E, Bayliss A, Beck JW, Bertrand C, Blackwell PG, Buck CE, Burr GS, Cutler KB, Damon PE, Edwards RL, Fairbanks RG, Friedrich M, Guilderson TP, Hughen KA, Kromer B, McCormac FG, Manning S, Bronk Ramsey C, Reimer RW,
Remmele S, Southon JR, Stuiver M, Talamo S, Taylor FW, van der Plicht J, Weyhenmeyer CE. 2004. IntCal04 terrestrial radiocarbon age calibration, 0-26 cal kyr BP. Radiocarbon 46(3):1029-58.

Shen C, Beer J, Liu T, Oeschger H, Bonani G, Suter M, Wölfli W. 1992. ${ }^{10} \mathrm{Be}$ in Chinese loess. Earth and Planetary Science Letters 109(1-2):169-77.

Wagner G, Beer J, Laj C, Kissel C, Masarik J, Muscheler R, Synal H-A. 2000. Chlorine-36 evidence for the Mono Lake event in the Summit GRIP ice core. Earth and Planetary Science Letters 181(1-2):1-6.

Wallbrink PJ, Murray AS. 1994. Fallout of ${ }^{7}$ Be in south eastern Australia. Journal of Environmental Radioactivity 25(3):213-28.

Wang YJ, Cheng H, Edwards RL, An ZS, Wu JY, Shen C-C, Dorale JA. 2001. A high-resolution absolutedated late Pleistocene monsoon record from Hulu Cave, China. Science 294:2345-8.

Wu ZK. 2004. High-resolution ${ }^{10} \mathrm{Be}$ record from the middle part of the Loess Plateau, and the reconstruction of East Asian Monsoon history over the last $130 \mathrm{ka}[\mathrm{PhD}$ dissertation]. Xi' an, China: Chinese Academy of Sciences, Xi' an Branch.

Yang S, Odah H, Shaw J. 2000. Variations in the geomagnetic dipole moment over the last 12,000 years. Geophysical Journal International 140(1):158-62.

Yuan D, Cheng H, Edwards RL, Dykoski CA, Kelly MJ, Zhang M, Qing J, Lin Y, Wang Y, Wu J, Dorale JA, An Z, Cai Y. 2004. Timing, duration, and transitions of the last interglacial Asian Monsoon. Science 304(5670): 575-8.

Zheng H, Rolph T, Shaw J, An Z. 1995. A detailed palaeomagnetic record for the last interglacial period. Earth and Planetary Science Letters 133(3-4):339-51.

Zhou LP, Oldfield F, Wintle AG, Robinson SG, Wang JT. 1990. Partly pedogenic origin of magnetite variations in Chinese loess. Nature 346(6286):737-9.

Zhou W, Head MJ, An Z, De Deckker P, Liu Z, Liu X, Lu X, Donahue D, Jull AJT, Beck JW. 2001. Terrestrial evidence for a spatial structure of tropical-polar interconnections during the Younger Dryas episode. Earth and Planetary Science Letters 191(3-4):231-9.

\section{APPENDIX}

\section{Loess Coring Procedures}

The cores collected at Luochuan comprised a series of overlapping short cores from 2 parallel transects. Each core had a rectangular profile of about $15 \times 15 \mathrm{~cm}^{2}$ and a length of about $40 \mathrm{~cm}$. They were collected so as to overlap by about $5 \mathrm{~cm}$ at each end. During subsampling for individual measurements, the overlapping $5 \mathrm{~cm}$ at each core section end was discarded.

\section{Magnetic Susceptibility (SUS) Measurement}

SUS is a measure of induced magnetization of objects in an artificial weak magnetic field. The principal carrier of the magnetization in the loess and paleosol is fine-grained magnetite and maghemite. 
The main carrier of the SUS signal is magnetic grains formed as an inorganic or biogenetic product of in situ pedogenesis (Maher and Taylor 1988; Maher and Thompson 1991; Zhou et al. 1990). SUS values directly reflect the intensity of pedogenesis and indirectly the amount of precipitation and intensity of the paleomonsoon (An et al. 1991). The SUS of the samples was measured in the laboratory using a Bartington MS2 susceptibility meter.

\section{${ }^{10}$ Be Sample Preparation}

${ }^{10} \mathrm{Be}$ was extracted from loess samples using the following procedure (Wu 2004):

1. After drying in oven at $70{ }^{\circ} \mathrm{C}$, approximately $1 \mathrm{~g}$ of sample was leached in $6 \mathrm{~N} \mathrm{HCl}$ along with $3 \mathrm{~mL}(30 \%) \mathrm{H}_{2} \mathrm{O}_{2}$ and $0.5 \mathrm{mg}{ }^{9} \mathrm{Be}$ carrier for $24 \mathrm{hr}$ in an ultrasonic bath.

2. Centrifuge sample solution at $4000 \mathrm{rpm}$ for $10 \mathrm{~min}$.

3. Dry the supernatant at $80{ }^{\circ} \mathrm{C}$ in a Teflon ${ }^{\circledR}$ beaker, then dissolve salts with $1 \mathrm{~N} 2 \mathrm{~mL} \mathrm{HCl}$, then centrifuge.

4. Add above supernatant to pretreated cation resin (Dowex 50WX-X8) column (plastic Bio-Rad column). The Be is eluted with $1 \mathrm{~N} \mathrm{HCl}$. Discard the first $30 \mathrm{~mL}$, then collect the next $80 \mathrm{~mL}$.

5. Adjust $\mathrm{pH}$ of this solution to 8-9, then 14 , then 8-9, in turn, with $(25 \%) \mathrm{NH}_{4} \mathrm{OH},(16 \%) \mathrm{NaOH}$, and $(25 \%) \mathrm{NH}_{4} \mathrm{OH}$, respectively. The Be should become a whitish $\mathrm{Be}(\mathrm{OH})_{2}$ gel at this $\mathrm{pH}$.

6. Centrifuge, discarding supernate.

7. Heat the $\mathrm{Be}(\mathrm{OH})_{2}$ in a platinum crucible to about $850-900{ }^{\circ} \mathrm{C}$ in an oven for $2 \mathrm{hr}$. This oxidizes the $\mathrm{Be}(\mathrm{OH})_{2}$ to $\mathrm{BeO}$.

8. Mix the $\mathrm{BeO}$ powder with 200-mesh $\mathrm{Cu}$ powder $(\mathrm{Cu}: \mathrm{BeO}=3: 1)$ and press into a $\mathrm{Cu}$ cathode for AMS analysis.

Depth, age, magnetic susceptibility, dry bulk density (DBD), and ${ }^{10} \mathrm{Be}$ concentration data are tabulated in Table 2.

Table 2 Measured quantities used for deducing geomagnetic and precipitation signals. Magnetic susceptibility, ${ }^{10} \mathrm{Be}$ concentration measurements, and time scale derivation are discussed in the Methods and Appendix sections. The age model and dry bulk density calculations were used to determine mass accumulation rate, which was then combined with ${ }^{10} \mathrm{Be}$ concentrations to calculate ${ }^{10} \mathrm{Be}$ fluxes.

\begin{tabular}{rllll}
\hline $\begin{array}{l}\text { Depth } \\
(\mathrm{cm})\end{array}$ & $\begin{array}{l}\text { Age } \\
(\mathrm{kyr} \mathrm{BP})\end{array}$ & $\begin{array}{l}{ }^{10} \mathrm{Be} \text { concentration } \\
(\mathrm{Be}(\mathrm{M}))\left(10^{6} \text { atoms } / \mathrm{g}\right)\end{array}$ & $\begin{array}{l}\text { Magnetic susceptibility } \\
(\mathrm{SUS}(\mathrm{M}))\left(10^{-8} \mathrm{~m}^{3} / \mathrm{kg}\right)\end{array}$ & $\begin{array}{l}\text { Dry bulk density } \\
\left(\mathrm{g} / \mathrm{cm}^{3}\right)\end{array}$ \\
\hline 1 & 0.09 & 213 & 120 & 1.74 \\
4 & 0.36 & 212 & 118.5 & 1.49 \\
8 & 0.73 & 215 & 119 & 1.37 \\
12 & 1.09 & 210 & 118.5 & 1.62 \\
16 & 1.45 & 213 & 118.5 & 1.51 \\
20 & 1.82 & 218 & 121 & 1.51 \\
24 & 2.18 & 219 & 121 & 1.59 \\
28 & 2.54 & 212 & 122 & 1.48 \\
32 & 2.91 & 231 & 125.5 & 1.5 \\
36 & 3.27 & 221 & 125.5 & 1.54 \\
40 & 3.64 & 220 & 128 & 1.53 \\
44 & 4 & 217 & 131 & 1.48 \\
48 & 4.36 & 224 & 131 & 1.45 \\
52 & 4.73 & 222 & 131.5 & 1.38 \\
56 & 5.09 & 192 & 128 & 1.39 \\
60 & 5.45 & 211 & 124 & 1.43 \\
64 & 5.82 & 212 & 124 & 1.42 \\
68 & 6.18 & 197 & 123 & 1.31
\end{tabular}


Table 2 Measured quantities used for deducing geomagnetic and precipitation signals. Magnetic susceptibility, ${ }^{10} \mathrm{Be}$ concentration measurements, and time scale derivation are discussed in the Methods and Appendix sections. The age model and dry bulk density calculations were used to determine mass accumulation rate, which was then combined with ${ }^{10} \mathrm{Be}$ concentrations to calculate ${ }^{10} \mathrm{Be}$ fluxes. (Continued)

\begin{tabular}{|c|c|c|c|c|}
\hline $\begin{array}{l}\text { Depth } \\
(\mathrm{cm})\end{array}$ & $\begin{array}{l}\text { Age } \\
(\mathrm{kyr} B \mathrm{BP})\end{array}$ & $\begin{array}{l}{ }^{10} \mathrm{Be} \text { concentration } \\
(\mathrm{Be}(\mathrm{M}))\left(10^{6} \text { atoms } / \mathrm{g}\right)\end{array}$ & $\begin{array}{l}\text { Magnetic susceptibility } \\
(\mathrm{SUS}(\mathrm{M}))\left(10^{-8} \mathrm{~m}^{3} / \mathrm{kg}\right)\end{array}$ & $\begin{array}{l}\text { Dry bulk density } \\
\left(\mathrm{g} / \mathrm{cm}^{3}\right)\end{array}$ \\
\hline 72 & 6.54 & 238 & 128 & 1.39 \\
\hline 76 & 6.91 & 211 & 134 & 1.38 \\
\hline 80 & 7.27 & 241 & 136 & 1.35 \\
\hline 84 & 7.63 & 237 & 149 & 1.42 \\
\hline 88 & 8 & 294 & 168.5 & 1.42 \\
\hline 92 & 8.36 & 269 & 166.5 & 1.38 \\
\hline 96 & 8.73 & 311 & 168 & 1.35 \\
\hline 100 & 9.09 & 276 & 164.5 & 1.43 \\
\hline 104 & 9.45 & 296 & 157 & 1.32 \\
\hline 108 & 9.82 & 270 & 157.5 & 1.42 \\
\hline 112 & 10.18 & 267 & 135 & 1.39 \\
\hline 116 & 10.54 & 228 & 133.5 & 1.32 \\
\hline 120 & 10.91 & 231 & 124.5 & 1.34 \\
\hline 124 & 11.27 & 235 & 115 & 1.36 \\
\hline 128 & 11.63 & 298 & 101 & 1.34 \\
\hline 132 & 13.07 & 230 & 108.5 & 1.36 \\
\hline 136 & 13.39 & 224 & 108 & 1.32 \\
\hline 140 & 13.71 & 226 & 113.5 & 1.29 \\
\hline 144 & 14.03 & 187 & 77.5 & 1.28 \\
\hline 148 & 14.35 & 167 & 76 & 1.23 \\
\hline 152 & 14.67 & 154 & 74 & 1.29 \\
\hline 156 & 14.99 & 168 & 72.5 & 1.33 \\
\hline 160 & 15.3 & 180 & 70 & 1.28 \\
\hline 164 & 15.62 & 168 & 81 & 1.37 \\
\hline 168 & 15.94 & 188 & 69.5 & 1.27 \\
\hline 172 & 16.26 & 167 & 72.5 & 1.35 \\
\hline 176 & 16.58 & 194 & 76.5 & 1.44 \\
\hline 180 & 16.9 & 169 & 76.5 & 1.32 \\
\hline 184 & 17.22 & 164 & 70.5 & 1.35 \\
\hline 188 & 17.53 & 168 & 72 & 1.29 \\
\hline 192 & 17.85 & 185 & 73.5 & 1.4 \\
\hline 196 & 18.17 & 178 & 71.5 & 1.36 \\
\hline 200 & 18.49 & 198 & 67 & 1.32 \\
\hline 204 & 18.81 & 162 & 59.5 & 1.33 \\
\hline 208 & 19.13 & 169 & 53.5 & 1.38 \\
\hline 212 & 19.45 & 154 & 54.5 & 1.36 \\
\hline 216 & 19.77 & 165 & 91 & 1.34 \\
\hline 217 & 19.84 & 191 & 92.5 & 1.35 \\
\hline 218 & 19.92 & 187 & 79 & 1.37 \\
\hline 219 & 20 & 159 & 67 & 1.4 \\
\hline 220 & 20.08 & 190 & 60 & 1.38 \\
\hline 221 & 20.16 & 164 & 55 & 1.35 \\
\hline 224 & 20.4 & 129 & 47 & 1.34 \\
\hline 228 & 20.72 & 137 & 49 & 1.3 \\
\hline 232 & 21.04 & 163 & 51.5 & 1.34 \\
\hline 236 & 21.36 & 145 & 51.5 & 1.31 \\
\hline 240 & 21.68 & 169 & 51.5 & 1.25 \\
\hline
\end{tabular}


Table 2 Measured quantities used for deducing geomagnetic and precipitation signals. Magnetic susceptibility, ${ }^{10} \mathrm{Be}$ concentration measurements, and time scale derivation are discussed in the Methods and Appendix sections. The age model and dry bulk density calculations were used to determine mass accumulation rate, which was then combined with ${ }^{10} \mathrm{Be}$ concentrations to calculate ${ }^{10} \mathrm{Be}$ fluxes. (Continued)

\begin{tabular}{|c|c|c|c|c|}
\hline $\begin{array}{l}\text { Depth } \\
(\mathrm{cm})\end{array}$ & $\begin{array}{l}\text { Age } \\
(\text { kyr BP) }\end{array}$ & $\begin{array}{l}{ }^{10} \mathrm{Be} \text { concentration } \\
(\mathrm{Be}(\mathrm{M}))\left(10^{6} \text { atoms } / \mathrm{g}\right)\end{array}$ & $\begin{array}{l}\text { Magnetic susceptibility } \\
(\mathrm{SUS}(\mathrm{M}))\left(10^{-8} \mathrm{~m}^{3} / \mathrm{kg}\right)\end{array}$ & $\begin{array}{l}\text { Dry bulk density } \\
\left(\mathrm{g} / \mathrm{cm}^{3}\right)\end{array}$ \\
\hline 244 & 22 & 149 & 57.5 & 1.3 \\
\hline 248 & 22.31 & 155 & 52.5 & 1.24 \\
\hline 252 & 22.63 & 147 & 48 & 1.24 \\
\hline 256 & 22.95 & 146 & 50 & 1.29 \\
\hline 260 & 23.27 & 155 & 59 & 1.28 \\
\hline 264 & 23.59 & 175 & 57 & 1.31 \\
\hline 268 & 23.91 & 146 & 56 & 1.31 \\
\hline 272 & 24.23 & 170 & 56 & 1.31 \\
\hline 276 & 24.54 & 149 & 54.5 & 1.35 \\
\hline 280 & 24.86 & 177 & 62 & 1.32 \\
\hline 284 & 25.18 & 151 & 57 & 1.32 \\
\hline 288 & 25.5 & 163 & 61 & 1.3 \\
\hline 292 & 25.82 & 158 & 63.5 & 1.3 \\
\hline 296 & 26.14 & 171 & 65 & 1.31 \\
\hline 300 & 26.46 & 192 & 66 & 1.32 \\
\hline 304 & 26.78 & 184 & 67 & 1.3 \\
\hline 308 & 27.09 & 203 & 75.5 & 1.29 \\
\hline 312 & 27.41 & 201 & 77 & 1.3 \\
\hline 316 & 27.73 & 197 & 77 & 1.28 \\
\hline 320 & 28.05 & 168 & 77.5 & 1.32 \\
\hline 324 & 28.37 & 208 & 78 & 1.3 \\
\hline 328 & 28.69 & 186 & 81 & 1.31 \\
\hline 332 & 29.01 & 202 & 81.5 & 1.34 \\
\hline 336 & 29.32 & 178 & 82.5 & 1.33 \\
\hline 340 & 29.64 & 214 & 82.5 & 1.32 \\
\hline 344 & 29.96 & 202 & 80.5 & 1.31 \\
\hline 348 & 30.28 & 224 & 82 & 1.35 \\
\hline 352 & 30.6 & 182 & 83.5 & 1.35 \\
\hline 356 & 30.92 & 221 & 84.5 & 1.35 \\
\hline 360 & 31.24 & 218 & 84.5 & 1.34 \\
\hline 364 & 31.55 & 221 & 86.5 & 1.34 \\
\hline 368 & 31.87 & 200 & 87 & 1.34 \\
\hline 372 & 32.19 & 217 & 87.5 & 1.31 \\
\hline 376 & 32.51 & 195 & 88.5 & 1.32 \\
\hline 380 & 32.83 & 217 & 90.5 & 1.35 \\
\hline 384 & 33.15 & 205 & 93 & 1.34 \\
\hline 388 & 33.47 & 220 & 91.5 & 1.33 \\
\hline 392 & 33.79 & 244 & 93.5 & 1.32 \\
\hline 396 & 34.1 & 225 & 97.5 & 1.34 \\
\hline 400 & 34.42 & 267 & 100 & 1.33 \\
\hline 404 & 34.74 & 234 & 97.5 & 1.35 \\
\hline 408 & 35.06 & 264 & 97.5 & 1.34 \\
\hline 412 & 35.38 & 231 & 99 & 1.37 \\
\hline 416 & 35.7 & 293 & 100.5 & 1.42 \\
\hline 420 & 36.02 & 240 & 101.5 & 1.4 \\
\hline 424 & 36.33 & 238 & 104 & 1.31 \\
\hline 428 & 36.65 & 246 & 100 & 1.38 \\
\hline
\end{tabular}


Table 2 Measured quantities used for deducing geomagnetic and precipitation signals. Magnetic susceptibility, ${ }^{10} \mathrm{Be}$ concentration measurements, and time scale derivation are discussed in the Methods and Appendix sections. The age model and dry bulk density calculations were used to determine mass accumulation rate, which was then combined with ${ }^{10} \mathrm{Be}$ concentrations to calculate ${ }^{10} \mathrm{Be}$ fluxes. (Continued)

\begin{tabular}{|c|c|c|c|c|}
\hline $\begin{array}{l}\text { Depth } \\
(\mathrm{cm})\end{array}$ & $\begin{array}{l}\text { Age } \\
(\mathrm{kyr} B P)\end{array}$ & $\begin{array}{l}{ }^{10} \mathrm{Be} \text { concentration } \\
(\mathrm{Be}(\mathrm{M}))\left(10^{6} \text { atoms } / \mathrm{g}\right)\end{array}$ & $\begin{array}{l}\text { Magnetic susceptibility } \\
(\mathrm{SUS}(\mathrm{M}))\left(10^{-8} \mathrm{~m}^{3} / \mathrm{kg}\right)\end{array}$ & $\begin{array}{l}\text { Dry bulk density } \\
\left(\mathrm{g} / \mathrm{cm}^{3}\right)\end{array}$ \\
\hline 432 & 36.97 & 263 & 102 & 1.4 \\
\hline 436 & 37.29 & 260 & 107 & 1.37 \\
\hline 440 & 37.61 & 257 & 108 & 1.4 \\
\hline 444 & 37.93 & 259 & 108.5 & 1.33 \\
\hline 448 & 38.25 & 240 & 107 & 1.27 \\
\hline 452 & 38.57 & 260 & 107.5 & 1.34 \\
\hline 456 & 38.88 & 242 & 106.5 & 1.39 \\
\hline 460 & 39.20 & 250 & 106 & 1.36 \\
\hline 464 & 39.52 & 234 & 105 & 1.38 \\
\hline 468 & 39.84 & 271 & 107 & 1.32 \\
\hline 472 & 40.16 & 255 & 107 & 1.36 \\
\hline 476 & 40.48 & 263 & 107.5 & 1.34 \\
\hline 480 & 40.80 & 232 & 107 & 1.33 \\
\hline 484 & 41.11 & 271 & 108.5 & 1.32 \\
\hline 488 & 41.43 & 259 & 107.5 & 1.27 \\
\hline 492 & 41.75 & 271 & 106.5 & 1.29 \\
\hline 496 & 42.07 & 274 & 105.5 & 1.33 \\
\hline 500 & 42.39 & 273 & 105.5 & 1.35 \\
\hline 504 & 42.71 & 272 & 107 & 1.32 \\
\hline 508 & 43.03 & 268 & 105.5 & 1.36 \\
\hline 512 & 43.34 & 271 & 106.5 & 1.34 \\
\hline 516 & 43.66 & 279 & 106 & 1.32 \\
\hline 520 & 43.98 & 268 & 103.5 & 1.33 \\
\hline 524 & 44.30 & 271 & 105 & 1.24 \\
\hline 528 & 44.62 & 259 & 107 & 1.35 \\
\hline 532 & 44.94 & 282 & 105.5 & 1.28 \\
\hline 536 & 45.26 & 248 & 107 & 1.30 \\
\hline 540 & 45.58 & 267 & 106 & 1.27 \\
\hline 544 & 45.89 & 240 & 105.5 & 1.28 \\
\hline 548 & 46.21 & 268 & 107 & 1.27 \\
\hline 552 & 46.53 & 247 & 107 & 1.28 \\
\hline 556 & 46.85 & 265 & 108.5 & 1.26 \\
\hline 560 & 47.17 & 260 & 108 & 1.28 \\
\hline 564 & 47.49 & 242 & 107.5 & 1.23 \\
\hline 568 & 47.81 & 249 & 110 & 1.13 \\
\hline 572 & 48.12 & 272 & 109 & 1.28 \\
\hline 576 & 48.44 & 258 & 109.5 & 1.25 \\
\hline 580 & 48.76 & 250 & 110.5 & 1.18 \\
\hline 584 & 49.08 & 245 & 110.5 & 1.20 \\
\hline 588 & 49.40 & 198 & 102.5 & 1.22 \\
\hline 592 & 49.72 & 220 & 101.5 & 1.25 \\
\hline 596 & 50.04 & 245 & 113.5 & 1.23 \\
\hline 600 & 50.36 & 228 & 115.5 & 1.23 \\
\hline 604 & 50.67 & 262 & 120.5 & 1.30 \\
\hline 608 & 50.99 & 262 & 126 & 1.26 \\
\hline 612 & 51.31 & 251 & 134 & 1.23 \\
\hline 616 & 51.63 & 219 & 125 & 1.23 \\
\hline
\end{tabular}




\section{$154 \quad$ W Zhou et al.}

Table 2 Measured quantities used for deducing geomagnetic and precipitation signals. Magnetic susceptibility, ${ }^{10} \mathrm{Be}$ concentration measurements, and time scale derivation are discussed in the Methods and Appendix sections. The age model and dry bulk density calculations were used to determine mass accumulation rate, which was then combined with ${ }^{10} \mathrm{Be}$ concentrations to calculate ${ }^{10} \mathrm{Be}$ fluxes. (Continued)

\begin{tabular}{|c|c|c|c|c|}
\hline $\begin{array}{l}\text { Depth } \\
(\mathrm{cm})\end{array}$ & $\begin{array}{l}\text { Age } \\
(\mathrm{kyr} B \mathrm{BP})\end{array}$ & $\begin{array}{l}{ }^{10} \mathrm{Be} \text { concentration } \\
(\mathrm{Be}(\mathrm{M}))\left(10^{6} \text { atoms } / \mathrm{g}\right)\end{array}$ & $\begin{array}{l}\text { Magnetic susceptibility } \\
(\mathrm{SUS}(\mathrm{M}))\left(10^{-8} \mathrm{~m}^{3} / \mathrm{kg}\right)\end{array}$ & $\begin{array}{l}\text { Dry bulk density } \\
\left(\mathrm{g} / \mathrm{cm}^{3}\right)\end{array}$ \\
\hline 620 & 51.95 & 251 & 126 & 1.23 \\
\hline 624 & 52.27 & 264 & 131 & 1.25 \\
\hline 628 & 52.59 & 258 & 135.5 & 1.19 \\
\hline 632 & 52.90 & 241 & 138.5 & 1.18 \\
\hline 636 & 53.22 & 266 & 137.5 & 1.21 \\
\hline 640 & 53.54 & 239 & 136 & 1.23 \\
\hline 644 & 53.86 & 272 & 140.5 & 1.19 \\
\hline 648 & 54.18 & 228 & 139 & 1.17 \\
\hline 652 & 54.50 & 249 & 132 & 1.18 \\
\hline 656 & 54.82 & 233 & 131.5 & 1.19 \\
\hline 660 & 55.13 & 237 & 124 & 1.26 \\
\hline 664 & 55.45 & 230 & 124.5 & 1.17 \\
\hline 668 & 55.77 & 252 & 115 & 1.20 \\
\hline 672 & 56.09 & 229 & 111.5 & 1.21 \\
\hline 676 & 56.41 & 237 & 113.5 & 1.25 \\
\hline 680 & 56.73 & 209 & 113 & 1.25 \\
\hline 684 & 57.05 & 238 & 108.5 & 1.25 \\
\hline 688 & 57.37 & 237 & 107.5 & 1.21 \\
\hline 692 & 57.68 & 225 & 108 & 1.19 \\
\hline 696 & 58.00 & 215 & 108.5 & 1.18 \\
\hline 700 & 58.32 & 242 & 98 & 1.22 \\
\hline 704 & 58.64 & 225 & 88.5 & 1.28 \\
\hline 708 & 58.96 & 227 & 83 & 1.30 \\
\hline 712 & 59.28 & 193 & 71 & 1.24 \\
\hline 716 & 59.60 & 198 & 62.5 & 1.29 \\
\hline 720 & 59.91 & 199 & 62.5 & 1.33 \\
\hline 724 & 60.23 & 186 & 61 & 1.37 \\
\hline 728 & 60.55 & 169 & 59 & 1.33 \\
\hline 732 & 60.87 & 192 & 57.5 & 1.27 \\
\hline 736 & 61.19 & 184 & 54.5 & 1.30 \\
\hline 740 & 61.51 & 179 & 55.5 & 1.29 \\
\hline 744 & 61.83 & 178 & 53.5 & 1.34 \\
\hline 748 & 62.14 & 166 & 54 & 1.36 \\
\hline 752 & 62.46 & 181 & 52.5 & 1.35 \\
\hline 756 & 62.78 & 187 & 53 & 1.39 \\
\hline 760 & 63.10 & 189 & 52.5 & 1.37 \\
\hline 764 & 63.42 & 194 & 54.5 & 1.39 \\
\hline 768 & 63.74 & 190 & 51.5 & 1.38 \\
\hline 772 & 64.06 & 184 & 52 & 1.34 \\
\hline 776 & 64.38 & 189 & 50 & 1.36 \\
\hline 780 & 64.69 & 166 & 48 & 1.32 \\
\hline 784 & 65.01 & 169 & 46.5 & 1.32 \\
\hline 788 & 65.33 & 170 & 44.5 & 1.31 \\
\hline 792 & 65.65 & 156 & 47 & 1.27 \\
\hline 796 & 65.97 & 147 & 42.5 & 1.28 \\
\hline 800 & 66.29 & 162 & 43 & 1.33 \\
\hline 804 & 66.61 & 149 & 43 & 1.33 \\
\hline 808 & 66.92 & 166 & 43.5 & 1.34 \\
\hline
\end{tabular}


Table 2 Measured quantities used for deducing geomagnetic and precipitation signals. Magnetic susceptibility, ${ }^{10} \mathrm{Be}$ concentration measurements, and time scale derivation are discussed in the Methods and Appendix sections. The age model and dry bulk density calculations were used to determine mass accumulation rate, which was then combined with ${ }^{10} \mathrm{Be}$ concentrations to calculate ${ }^{10} \mathrm{Be}$ fluxes. (Continued)

\begin{tabular}{|c|c|c|c|c|}
\hline $\begin{array}{l}\text { Depth } \\
(\mathrm{cm})\end{array}$ & $\begin{array}{l}\text { Age } \\
(\text { kyr BP) }\end{array}$ & $\begin{array}{l}{ }^{10} \mathrm{Be} \text { concentration } \\
(\mathrm{Be}(\mathrm{M}))\left(10^{6} \text { atoms } / \mathrm{g}\right)\end{array}$ & $\begin{array}{l}\text { Magnetic susceptibility } \\
(\mathrm{SUS}(\mathrm{M}))\left(10^{-8} \mathrm{~m}^{3} / \mathrm{kg}\right)\end{array}$ & $\begin{array}{l}\text { Dry bulk density } \\
\left(\mathrm{g} / \mathrm{cm}^{3}\right)\end{array}$ \\
\hline 812 & 67.24 & 151 & 44 & 1.29 \\
\hline 816 & 67.56 & 165 & 43.5 & 1.28 \\
\hline 820 & 67.88 & 153 & 42 & 1.30 \\
\hline 824 & 68.20 & 163 & 42.5 & 1.27 \\
\hline 828 & 68.52 & 148 & 42.5 & 1.28 \\
\hline 832 & 68.84 & 160 & 41.5 & 1.25 \\
\hline 836 & 69.15 & 149 & 42.5 & 1.26 \\
\hline 840 & 69.47 & 162 & 45.5 & 1.29 \\
\hline 844 & 69.79 & 171 & 48 & 1.27 \\
\hline 848 & 70.11 & 164 & 48 & 1.30 \\
\hline 852 & 70.43 & 168 & 49 & 1.24 \\
\hline 856 & 70.75 & 176 & 53 & 1.22 \\
\hline 860 & 71.07 & 162 & 50 & 1.21 \\
\hline 864 & 71.39 & 157 & 54 & 1.15 \\
\hline 868 & 71.70 & 174 & 64 & 1.26 \\
\hline 872 & 72.02 & 191 & 70.5 & 1.24 \\
\hline 876 & 72.34 & 208 & 72.5 & 1.22 \\
\hline 880 & 72.66 & 203 & 74 & 1.23 \\
\hline 884 & 72.98 & 196 & 72 & 1.25 \\
\hline 888 & 73.30 & 195 & 71.5 & 1.26 \\
\hline 892 & 73.62 & 199 & 72 & 1.24 \\
\hline 896 & 73.93 & 200 & 71 & 1.27 \\
\hline 900 & 74.25 & 203 & 68 & 1.28 \\
\hline 904 & 74.57 & 197 & 62 & 1.27 \\
\hline 908 & 74.89 & 191 & 55.5 & 1.25 \\
\hline 912 & 75.21 & 182 & 53 & 1.28 \\
\hline 916 & 75.53 & 196 & 56 & 1.27 \\
\hline 920 & 75.85 & 175 & 48 & 1.24 \\
\hline 924 & 76.17 & 174 & 48 & 1.27 \\
\hline 928 & 76.48 & 174 & 49 & 1.36 \\
\hline 932 & 76.80 & 172 & 43.5 & 1.23 \\
\hline 936 & 77.12 & 161 & 38.5 & 1.28 \\
\hline 940 & 77.44 & 160 & 37.5 & 1.28 \\
\hline 944 & 77.76 & 164 & 41 & 1.28 \\
\hline 948 & 78.08 & 160 & 47 & 1.26 \\
\hline 952 & 78.40 & 171 & 49 & 1.28 \\
\hline 956 & 78.71 & 171 & 52 & 1.26 \\
\hline 960 & 79.03 & 181 & 53 & 1.26 \\
\hline 964 & 79.35 & 195 & 57 & 1.30 \\
\hline 968 & 79.67 & 208 & 70.5 & 1.29 \\
\hline
\end{tabular}

\section{Age Calibration Using Radiocarbon Dates}

${ }^{14} \mathrm{C}$ dating of the samples used for establishing the time scale in the section $<12 \mathrm{kyr}$ cal BP was performed at the NSF-Arizona AMS Facility (Table 3). Sample preparation took place at the Institute of Earth Environment in Xi' an. The ${ }^{14} \mathrm{C}$ ages were calibrated using OxCal v 3.10 (Bronk Ramsey 2001) and the IntCal04 calibration curve (Reimer et al. 2004). 
Table $3{ }^{14} \mathrm{C}$ ages used for calibrating the younger part of the investigated loess sequence (depth $<130 \mathrm{~cm})$.

\begin{tabular}{lllllll}
\hline Material & Lab code & $\begin{array}{l}\text { Depth } \\
(\mathrm{cm})\end{array}$ & $\begin{array}{l}\delta^{13} \mathrm{C} \\
(\%)\end{array}$ & $\begin{array}{l}{ }^{14} \mathrm{C} \text { age } \pm 2 \sigma \\
(\mathrm{yr} \mathrm{BP})\end{array}$ & $\begin{array}{l}\text { Calibrated range } \\
(\mathrm{yr} \mathrm{BP})\end{array}$ & $\begin{array}{l}\text { Mean calibrated } \\
(\mathrm{yr} \mathrm{BP})\end{array}$ \\
\hline XLLQ1056 & AA-44668 & 28 & -25 & $2160 \pm 40$ & $2040-2320$ & $2180 \pm 140$ \\
XLLQ1087 & AA-44696 & 53 & -25 & $3920 \pm 65$ & $4150-4530$ & $4340 \pm 190$ \\
XLLQ1986B & AA-44695 & 75 & -25 & $6340 \pm 70$ & $7150-7430$ & $7290 \pm 140$ \\
\hline
\end{tabular}

\section{Age Calibration Using OSL Dates}

Luminescence measurements (Table 4) of all quartz aliquots were undertaken using an automated Daybreak $2200 \mathrm{TL} / \mathrm{OSL}$ reader with a ${ }^{90} \mathrm{Sr} /{ }^{90} \mathrm{Y}$ beta source for irradiation. Optical stimulation with blue LEDs $(470 \pm 5 \mathrm{~nm})$ was performed at $125^{\circ} \mathrm{C}$, and OSL emission was detected through two 3mm U-340 filters. For all samples, neutron activation analysis (NAA) was used to measure the uranium and thorium concentrations, and $\mathrm{K}$ content was determined by flame spectrum analysis. Dose rate was calculated according to (Aitken 1998).

Table 4 OSL ages of loess samples used for calibrating the older portion of the investigated loess sequence (deeper than $130 \mathrm{~cm}$ ).

\begin{tabular}{|c|c|c|c|c|c|c|c|c|}
\hline $\begin{array}{l}\text { Lab } \\
\text { code }\end{array}$ & $\begin{array}{l}\text { Depth } \\
(\mathrm{cm})\end{array}$ & $\begin{array}{l}\mathrm{U} \\
(\mathrm{ppm})\end{array}$ & $\begin{array}{l}\text { Th } \\
(\mathrm{ppm})\end{array}$ & $\begin{array}{l}\mathrm{K} \\
(\%) \\
\end{array}$ & $\begin{array}{l}\text { Water content } \\
(\%)\end{array}$ & $\begin{array}{l}\text { Dose } \\
(\mathrm{Gy} / \mathrm{kyr})\end{array}$ & $\begin{array}{l}\text { Equi. dose } \\
\text { (Gy) }\end{array}$ & $\begin{array}{l}\text { Age } \\
(\text { kyr BP) }\end{array}$ \\
\hline IEE630 & 128 & $2.83 \pm 0.14$ & $12.45 \pm 0.27$ & 1.87 & $15 \pm 3$ & $3.72 \pm 0.2$ & $39.42 \pm 0.84$ & $10.6 \pm 0.62$ \\
\hline IEE631 & 138 & $2.73 \pm 0.15$ & $11.87 \pm 0.27$ & 1.71 & & $3.5 \pm 0.19$ & $43.55 \pm 0.98$ & $12.44 \pm 0.74$ \\
\hline IEE170 & 210 & $2.57 \pm 0.11$ & $12.21 \pm 0.13$ & 1.81 & & $3.58 \pm 0.19$ & $60.7 \pm 2.2$ & $16.95 \pm 1.1$ \\
\hline IEE395 & 400 & $2.51 \pm 0.13$ & $12.04 \pm 0.26$ & 1.61 & & $3.34 \pm 0.19$ & $131.6 \pm 5.4$ & $39.4 \pm 2.7$ \\
\hline IEE171 & 480 & $2.58 \pm 0.1$ & $11.71 \pm 0.14$ & 1.95 & & $4 \pm 0.37$ & $173.3 \pm 8.2$ & \pm 3.9 \\
\hline IEE396 & 520 & & & 1.69 & & $3.21=$ & & \pm 3.16 \\
\hline IEE172 & 710 & $2.49 \pm 0.11$ & $11.65 \pm 0.14$ & 1.83 & & $3.16 \pm 0.18$ & $181.2=$ & $57.43 \pm 3.61$ \\
\hline IEE397 & 780 & $2.46 \pm 0.11$ & $11.33 \pm 0.25$ & 1.53 & $15 \pm 5$ & $3.15 \pm 0.18$ & $210.8 \pm 6.4$ & $66.95 \pm 4.3$ \\
\hline IEE398 & 910 & $2.71 \pm 0.12$ & $11.91 \pm 0.26$ & 1.39 & $22 \pm 3$ & $2.88 \pm 0.17$ & $212.8 \pm 4.8$ & $74.02 \pm 4.74$ \\
\hline IEE173 & 920 & $2.75 \pm 0.1$ & $12.48 \pm 0.14$ & 1.86 & $25 \pm 3$ & $3.1 \pm 0.15$ & $231.7 \pm 7.8$ & $74.7 \pm 4.31$ \\
\hline
\end{tabular}

The fine-grained (4-11 $\mu \mathrm{m})$ quartz grains were extracted from the loess samples for luminescence dating. Equivalent dose values were determined by sensitivity-corrected multiple aliquot regenerative-dose protocol, which enabled us to recover equivalent dose values with high accuracy and precision in Chinese loess (Lu et al. 2007). Preheating conditions are $260{ }^{\circ} \mathrm{C}\left(10\right.$ seconds) and $220^{\circ} \mathrm{C}$ (10 seconds) for natural/regeneration OSL $\left(\mathrm{L}_{\mathrm{i}}\right)$ and test dose OSL $\left(\mathrm{T}_{\mathrm{i}}\right)$ responses, respectively. The OSL signal from the first 5 seconds and subtracted that from the last 5 seconds of the decay curve has been applied to construct dose regenerative growth curve of the corrected OSL intensity $\left(L_{i} / T_{i}\right)$ and to determine equivalent dose value.

\section{Propagation of Errors}

We report measurement uncertainties on ${ }^{10} \mathrm{Be}$ concentrations of $3 \%$, and magnetic susceptibility uncertainties of $\pm 1\left(\times 10^{-8} \mathrm{~m}^{3} / \mathrm{kg}\right)$. Propagation of uncertainties in calculated results were made using standard statistical methods (Bevington and Robinson 1969; Jeter 2003). An estimate and uncertainty for SUS(D) of $25.1 \pm 3.5\left(\times 10^{-8} \mathrm{~m}^{3} / \mathrm{kg}, 1 \sigma\right)$ was obtained from linear least-square hyperbolic mixing model through the coercivity vs. susceptibility data shown in Figure 3. These uncertainties were graphically propagated through the linear least-squares model $(2 \sigma)$ uncertainty envelope surrounding the plot of $\mathrm{Be}(\mathrm{M})$ vs. SUS(M) (Figure $4 \mathrm{~b}$ ), to yield a value and uncertainty for the ${ }^{10} \mathrm{Be}$ dust 
endmember $\operatorname{Be}(\mathrm{D})\left(136.4 \pm 6.25\left[\times 10^{6}\right.\right.$ atoms/g, $\left.\left.1 \sigma\right]\right)$. As by convention, for the regression calculations of SUS(M) vs. $\mathrm{Be}(\mathrm{M})$, all analytical errors were assigned to the dependent-variable $(\mathrm{Be}(\mathrm{M}))$ assuming the errors were not covariant. Uncertainties in SUS(D) and Be(D) were quadratically combined with measurement errors on SUS $(M)$ and $B(M)$ to determine uncertainties for SUS(P) and $\mathrm{Be}(\mathrm{P}, \mathrm{GM})$. Average propagated $(1 \sigma)$ uncertainties on SUS(P) are 3.64 (SI Units) and $7.1 \%$ for $\mathrm{Be}(\mathrm{P}, \mathrm{GM})$ values. A linear model dependence between $\mathrm{SUS}(\mathrm{P})$ and $\mathrm{Be}(\mathrm{P}, \mathrm{GM})$ is assumed (Figure $4 \mathrm{~d})$. This linear model is subtracted from $\mathrm{Be}(\mathrm{P}, \mathrm{GM})$ to yield values for $\mathrm{Be}(\mathrm{GM})$ and $\mathrm{Be}(\mathrm{P})$. We assert the linear trend in this plot is due to precipitation amount, but that much of the observed scatter is not noise but rather is due to the second independent variable, i.e. geomagnetic field variations. As it is not possible to independently determine how much scatter is due to noise vs. field variations, the errors in the model results $\mathrm{Be}(\mathrm{GM})$ and $\mathrm{Be}(\mathrm{P})$ are assumed to be equivalent to those determined for $\mathrm{Be}(\mathrm{P}, \mathrm{GM})$. $\mathrm{Be}(\mathrm{GM})$ concentrations were converted to fluxes using the linear age model-based accumulation rates (see Figure 7), with errors on $\mathrm{Be}(\mathrm{GM})_{\text {flux }}$ expanded to account for standard error in the slope of the age vs. depth model relationship $(2.3 \%)$. Normalization of $\mathrm{Be}(\mathrm{GM})_{\text {flux }}$ to modern ${ }^{10} \mathrm{Be}$ production rate is assumed to not increase fractional uncertainty on normalized $\mathrm{Be}(\mathrm{GM})_{\text {flux }}$. Errors on normalized $\mathrm{Be}(\mathrm{GM})_{\text {flux }}$ were propagated through the global mean ${ }^{10} \mathrm{Be}$ power law production rate equation of Masarik and Beer (1999). Uncertainties of 7\% $(1 \sigma)$ in ${ }^{10} \mathrm{Be}$ production rates (Masarik and Beer 1999) were used in combination with calculated model errors on normalized $\mathrm{Be}(\mathrm{GM})_{\mathrm{flux}}$. Median uncertainties on calculated M/Mo (Figure $5 \mathrm{~b}$ ) is $14 \%$ with a mean uncertainty of $21 \%$. The large difference between mean and median uncertainties is due to a relatively small number ( 15 of 116) of model M/Mo values from the LGM and MIS4 with very large uncertainties (between $30-100 \%, 1 \sigma$ ). The reason for the large uncertainties in these few samples is due to low precipitation during the LGM and MIS4, resulting in low $\mathrm{Be}(\mathrm{P}, \mathrm{GM})$ fluxes, which after subtraction of $\mathrm{Be}(\mathrm{P})$ resulted in even lower calculated $\mathrm{Be}(\mathrm{GM})$ fluxes with proportionally high uncertainties.

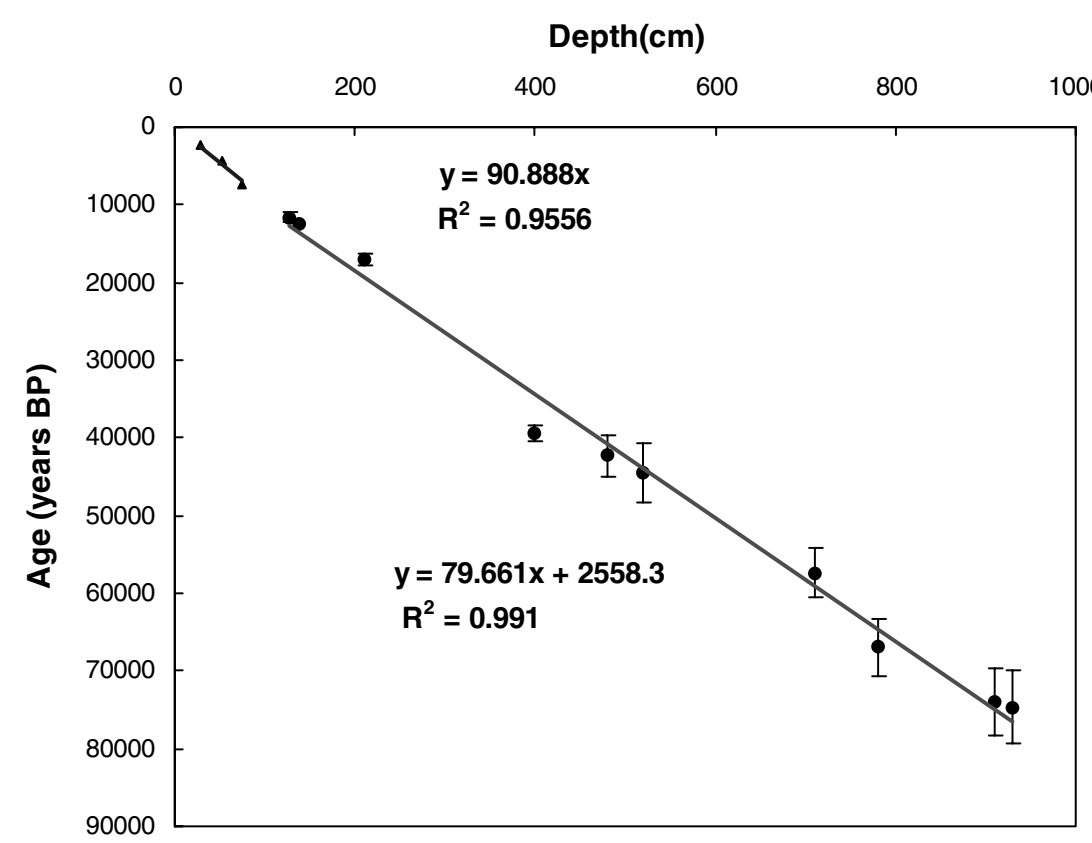

Figure 7 Plot of all data used for age calibration of the loess sequence. ${ }^{14} \mathrm{C}$ and OSL data are shown together with their corresponding regression lines $\left(<10\right.$ and $>10 \mathrm{kyr} \mathrm{BP}$, respectively). The ${ }^{14} \mathrm{C}$ ages were used for calibrating the younger part (depth $<130 \mathrm{~cm})$. The OSL ages were used for calibrating the older part (depth $>130 \mathrm{~cm})$. 
Uncertainties for paleorainfall amount (Figure 6) used calculated uncertainties for $\mathrm{Be}(\mathrm{P})_{\text {flux }}$ (average $7.03 \%, 1 \sigma)$, which were calculated using the same method as for $\mathrm{Be}(\mathrm{GM})_{\text {flux }}$ uncertainties. The uncertainty in tropospheric ${ }^{10} \mathrm{Be} /{ }^{7} \mathrm{Be}$ is not well known. As such, we arbitrarily assigned a 5\% (1 $\left.\sigma\right)$ uncertainty to this ratio. These uncertainties were combined with uncertainties in slope and intercept of the plot of ${ }^{7} \mathrm{Be}$ vs. annual rainfall for the 3 modern sites evaluated to yield average uncertainties for model paleoprecipitation estimates of $19.5 \%(1 \sigma)$. 